\title{
ИЗБЫТОЧНАЯ СМЕРТНОСТЬ В РОССИИ В ПРАЗДНИЧНЫЕ ДНИ
}

\author{
АЛЕКСАНДР НЕМЦОВ, АНАТОЛИЙ СИМОНОВ, \\ ТИМУР ФАТТАХОВ, РОМАН ГРИДИН
}

Постановка проблемы. Известно, что праздники сопровождаются ростом заболеваемости и смертности. Целью данного исследования являлось обобщение опыта предыдущих работ, изучающих связь между национальными праздниками и временем смерти, а также анализ российских особенностей смертности в праздничные дни. Мы ставили следующие вопросы: 1) «увеличивается ли в России риск умереть в праздники?»; 2) «если да, то в какие?»; 3) «связано ли это со злоупотреблением алкоголем?»; 4) «в какой степени в это вовлечены мужчины и женщины?»; 5) «какова оценка избыточного числа смертей в праздничные дни?».

Методы. В исследовании использованы ежедневные данные о числе умерших в России от всех причин и от алкогольных отравлений с разделением по полу за 2000-2017 г2. Всего в рассматриваемый период умерло 35,4 млн человек. Исследовали 9 государственных праздников в России. За ноль отсчета принимали скользящую среднюю LOWESS, рассчитанную для непраздничных дней и экстраполированную на праздничные дни. Учитывали праздничные дни, которые превышали доверительный интервал LOWESS. Для оченки потерь в день рождения за ноль отсчета принимали линейную регрессию и ее доверительный интервал. Для косвенной оценки легального и нелегального потребления алкоголя использовали даннье Росстата о помесячных продажах алкогольной продукции и данные Google Trends o популярности поисковых запросах на алкогольную продукцию.

Результаты. Пять из девяти государственных праздников в России сопровождаются ростом числа смертей. Наибольший рост наблюдается 1-15 января в связи с Новым годом. В это время избыточное число смертей составило 113,6 тыс. человек за 18 лет или 6,3 тыс. человек в год с максимумом 1 января (2,0 тысячи в день). Это на 14,0\% больше, чем в будни. В праздники 23 февраля, 8 марта и 9 мая избыточное число смертей составило в сумме 1,7 тыс. в год. 80,9\% избыточных смертей в январе приходится на мужчин. Общая смертность и смертность при отравлении алкоголем совпадает по максимуму 1 января и в последующей динамике. После 2005 г., когда увеличилась продолжительность новогодних праздников, максимум 1 января и последующая динамика смертности не изменилась. Годовоймаксимум продаж алкогольных напитков приходится на декабрь. Дни рождения также сопровождаются приращением общей смертности на 11,1 тыс. в год, и это также связано с алкоголизацией.

Заключение. В России в праздники, главным образом новогодние и дни рождения, происходит значительный прирост смертности, который обусловлен преимущественно злоупотреблением алкоголем и не зависит от продолжительности праздников в январе. Снизить этот урон может уменьшение доступности крепкого алкоголя, максимум продаж которого приходится на декабрь.

Ключевые слова: праздники, день рождения, смертность, избыточная смертность, отравления алкоголем, Россия, мужчины, женщцины.

АЛЕКСАНДР ВИКЕНТЬЕВИЧ НЕМЦОВ (nemtsov33@gmail.com), НАЦИОНАЛЬНЫЙ НАУЧНЫЙ ЦЕНТР НАРКОЛОГИИ МЗ РФ, РОССИЯ.

АНАТоЛИЙ НИКИФоРОвИч СИмонов (anatoly.simonov@psychiatry.ru), ЦЕНТР ПСихиЧЕСКОГО зДОРОвья, Россия.

ТИМУР АСФАНОВИч ФАТТАХОВ (timur300385@mail.ru), НАЦИОНАЛЬНЫЙ ИССЛЕДОВАТЕЛЬСКИЙ УНИВЕРСИТЕТ «ВЫСШАЯ ШКОЛА ЭКОНОМИКИ», РОССИЯ.

РОМАН ВЛАДИМИРОВИч ГРИДИН (rvgridin@gmail.com), ЦЕНТР РАЗВИТИЯ ПОТРЕБИТЕЛЬСКОГО РЫНКА МОСКОВСКОЙ ШКОЛЫ УПРАВЛЕНИЯ СКОЛКОВО, РОССИЯ.

В СТАТЬЕ БЫЛИ ЧАСТИЧНО ИСПОЛЬЗОВАНЫ РЕЗУЛЬТАТЫ, ПОЛУЧЕННЫЕ В РАМКАХ ПРОГРАММЫ ФУНДАМЕНТАЛЬНЫХ ИССЛЕДОВАНИЙ НИУ ВШЭ.

СТАТЬЯ ПОСТУПИЛА В РЕДАКЦИЮ В ДЕКАБРЕ 2020 Г. 


\section{ВВЕДЕНИЕ}

Праздники - важное время в жизни людей, это способ отвлечься от повседневности, изменить обычный ритм жизни. Во многих культурах праздники часто связывают с неумеренным потреблением алкоголя, который, как считается, помогает людям расслабиться и развлечься. Действительно, праздники добавляют веселья, но иногда уровень и структура потребления становятся не только вредными для здоровья, но и фатальными для жизни. Это явление изучали неоднократно.

Начальные исследования проводили на основе месячных показателей, которые позволили обнаружить максимальный рост смертности в декабре-январе (Kloner, Poole, Perritt 1999: 1630). Однако позже стали доступны более детальные данные, которые привлекли внимание исследователей к новогодне-рождественским праздникам. Было показано, что во время этих праздников и в связи с ними наблюдается рост смертей от внешних причин, таких как самоповреждения (non-fatal deliberate self-harm) (Bergen, Hawton 2007: 855), самоубийства и убийства (Ajdacic-Gross et al. 2012: 603). Изучались также ненасильственные причины смерти, такие как сердечно-сосудистые заболевания (Kloner, Poole, Perritt 1999: 1630; Phillips et al. 2004: 3781) и патологии дыхательной системы (Milne 2005: 849). Во всех этих случаях отмечен рост смертности в праздники. В США пики числа смертей в связи с заболеванием сердца приходились на Рождество и Новый год со снижением между ними (Phillips et al. 2004: 3781). В отличие от США в Великобритании пик числа смертей приходился на Новый год, но не Рождество или Пасху (Milne 2005: 849). Более детализированное исследование в США подтвердило, что самый большой пик числа смертей в году приходится на Рождество. За этим пиком с некоторым отрывом следует Новый год, а далее по нисходящей - День благодарения, День независимости, День труда и День памяти. В День Президентов прироста числа смертей не обнаружено (Phillips, Barker, Brewer 2010: 1463).

В качестве факторов повышения смертности в новогодне-рождественские праздники называли переедание и алкоголизацию, снижение качества медицинской помощи, снижение чувства опасности в случае заболевания в эти дни, что откладывало обращение за медицинской помощью, а также заболеваемость в связи с низкой температурой. Последнее следует считать случайным совпадением Рождества и зимнего времени года, так как в Новой Зеландии, где эти праздники приходятся на летний период (Южное полушарие), также растет число смертей в Рождество и Новый год (Knight et al. 2016: е005098). Следует отметить, что на материале западных стран алкогольный фактор выступает не как первый, а как равнозначный среди других.

Интересно, что в Кувейте (мусульманская страна) поступление больных в крупную больницу в 1,5 раза увеличивалось на второй день праздника Ураза Байрам - одного из двух главных мусульманских праздников в середине лета (Zubaid, Thalib, Suresh 2006: 191).

Смертность в связи с еще одним распространенным праздником (днем рождения) в России обсуждалась только в СМИ, чаще в виде пересказов западных источников. 
Первые исследования этой проблемы за рубежом относятся к 1970-м годам, когда был отмечен так называемый «эффект дня рождения» - статистический феномен совпадения роста смертности и месяца рождения в Англии и Уэльсе (Anderson 1975: 151). Позже это подтвердилось на ежедневных данных в Швейцарии (Bovet, Spagnoli, Sudan 1997: 151), в постсоветской Украине (Vaiserman et al. 2003: 221) и США (Ajdacic-Gross et al. 2012: 603). Эффект дня рождения иногда проявлялся только у мужчин (Phillips, Van Voorhees, Todd 1992: 532), но чаще без гендерных различий (Doblhammer 1999: 1; Medenwald, Kuss 2014: е004423). В США было показано также, что эффект дня рождения чаще наблюдается в возрасте 20-39 лет (51,0\%), до этого возраста - в 31,3\% случаев, а после 39 лет резко убывает (возраст 90+-4,3\%). При этом совпадение дня рождения и выходного дня резко повышает риск умереть. Всего в США за 13 лет (1998-2011 гг.) избыточная смертность в день рождения составила 4590 случаев (Реп̃a 2015: 59) или 353 в год. Указывалось также, что этот эффект может быть статистическим артефактом из-за ошибок учета (Abel, Kruger 2009: 175; Phillips, Van Voorhees, Todd 1992: 532). В качестве факторов роста смертности в дни рождения обычно указывали на злоупотребление алкоголем, напряжение, связанное с днем рождения, и самоубийство.

Важно отметить, что к самоубийствам в день рождения в зарубежной литературе проявлен особый интерес. Например, для Японии показан полуторакратный рост числа самоубийств в день рождения (Motohashi 2012: 1282). В Японии также было показано, что у мужчин рост суицидов происходит за 5 дней до и неделю после дня рождения с максимумом в день рождения, у женщин этот интервал был шире. При этом период повышенного риска самоубийств зависел от возраста и социального положения умерших (Stickley et al. 2016: 259). В Германии (Бавария) рост самоубийств в день рождения не обнаружен (Reulbach et al. 2007: 554) в отличие от Великобритании (Williams et al. 2011: 13). В последнем случае отмечалось, что риск суицида выше у людей, обращавшихся недавно за психиатрической помощью.

Как видно, проблема роста смертности в праздники в зарубежных публикациях разрабатывалась довольно активно. В России, несмотря на высокий уровень потребления алкоголя и его тяжелые последствия, только однажды было зафиксировано повышение сердечно-сосудистой и общей смертности 2-5 января в ограниченной географической точке (г. Кемерово) (Барабаш, Алтарев, Фомина 2010: 35) или рост убийств в Новый год (Жаксымбаев 2012).

\section{ЦЕЛЬ ИССЛЕДОВАНИЯ}

Целью данного исследования являлось обобщение опыта предыдущих работ, изучающих связь между национальными праздниками и временем смерти, а также анализ российских особенностей смертности в праздничные дни. Мы ставили следующие вопросы: 1) «увеличивается ли в России риск умереть в праздники?»; 2) «если да, то в какие?»; 3) «связано ли это со злоупотреблением алкоголем?»; 4) «в какой степени в это вовлечены мужчины и женщины?»; 5) «какова оценка избыточного числа смертей в праздничные дни?». 


\section{МАТЕРИАЛ И МЕТОДЫ}

Проведено эпидемиологическое ретроспективное невыборочное исследование. Работу проводили в несколько этапов в зависимости от характера праздников и структуры материала. На первом этапе исследования смертность в государственные праздники России анализировали на временных рядах ежедневной статистики смертности за период 20002017 гг. Данные о ежедневном числе умерших доступны с 2000 г. и были получены с помощью специальной разработки собранных Росстатом анонимных микроданных сплошной регистрации случаев смерти. Для анализа использовали временные ряды ежедневных чисел умерших от всех причин смерти раздельно для мужчин и женщин (всего 18,5 и 16,9 млн умерших за период соответственно) и от случайных отравлений алкоголем, которые были определены нами как сумма кодов X45 (случайное отравление алкоголем) и Y15 (отравление алкоголем с неопределенными намерениями) МКБ-10. В России в последние годы произошло резкое увеличение смертей от Ү15. Это, вероятно, происходило за счет ошибочного кодирования части смертей X45 как смерти Y15. Всего за анализируемый период было выявлено 501,5 тыс. смертей от Ү15. Смерти без указания даты были исключены из исследования $(0,041 \%)$, как и данные об умерших 29 февраля (5 дней в 2000-2017 гг.).

В этой части работы для оценки избыточного числа смертей годичные отрезки ряда ежедневных смертей в 2000-2017 гг. были суммированы. В ряду $(n=365)$ учитывали 7 главных праздников в России: Новый год (1 января), православное Рождество (7 января), старый Новый год (14 января), День защитника Отечества (23 февраля), Международный женский день (8 марта), Праздник Весны и Труда (1 мая), День Победы (9 мая), День России (12 июня) и День народного единства (12 декабря).

Поскольку рост числа смертей в праздники продолжался 2 и более дней, общее количество дней повышенной смертности составило 22 дня. Для двух официальных праздников (День России и День народного единства) не обнаружили роста числа смертей, их учитывали в исследовании как будние дни.

На первом этапе из ежедневных показателей общей смертности и при отравлении алкоголем в 2000-2017 гг. после суммирования $(\mathrm{n}=365)$ выделяли 2 ряда: смерти в праздники и смерти в будни с исключением праздничных дней и артефактов «последнеепервое число месяцев». Для смертности в будни был построен тренд, который затем был экстраполирован на праздничные дни.

Для описания тренда будней использовали метод LOWESS (LOcally WEighted Scatter-plot Smoother) или локально взвешенную полиномиальную регрессию (Cleveland, Devlin 1988: 596). Точность подгонки линии тренда под наблюдаемые данные (fitting) регулировали при помощи параметра сглаживания (bandwidth). Для тренда LOWESS строили доверительный интервал 95\%. Дополнительную смертность в праздники определяли как разность между реально наблюдаемой ежедневной смертностью и экстраполированной на праздничные дни будничной смертностью в эти дни. Учитывали только те праздничные дни, которые превышали доверительный интервал. 
Поскольку линия тренда будней имела пропуски в праздничные дни месяца, требовалось заполнить эти пропуски. Для заполнения пропущенных точек линии тренда и вычислений использовали линейную интерполяцию, состоящую в том, что крайние точки пропущенного ряда соединяются друг с другом прямой линией.

Ряд общей смертности имел 11 дефектов первичного учета данных с февраля по декабрь (см. Обсуждение результатов): пик в первый день месяца и минимум за день до этого. Иногда эти пики расширялись до двух дней - всего 35 дней, которые были исключены из ряда будних дней (9,2\% смертей от общего числа), в их числе праздник 1 мая. Пропуски были заполнены так же, как пропуски праздничных дней. Минимум общей смертности 31 декабря не выходил за доверительный интервал 95\%, а ряд смертей от случайных отравлений алкоголем таких дефектов не имел.

Второй этап - исследование смертности в связи с праздником дня рождения. Предварительно были исключены умершие 1 января, поскольку день смерти части из них зарегистрирован в этот день ошибочно. Для анализа смертности в связи с днем рождения использовали следующий алгоритм. Дни смерти и рождения каждого умершего были пронумерованы в соответствии с номерами дней в году (от 1 до 365/366). Далее из номера дня рождения вычитали номер дня смерти. В случае совпадения номера дня рождения (ДР) и смерти (ДС) разность равнялась нулю. Если разность между номером ДР и ДС попадала в интервал \pm 182 , разности сохраняли соответствующие значения со знаком + или -. Если же разность выходила за границы \pm 182 дня, то проводили дополнительное вычисление по формуле 365(366)-ДС+ДР. В результате получали распределение ДС всех умерших по отношению к их ДР на шкале \pm 182 дня.

Третий этап - исследование потребления алкоголя, легального и нелегального. Были использованы официальные статистические данные Росстата о продажах алкоголя ${ }^{1}$. Косвенным индикатором нелегального потребления алкоголя служили поисковые запросы о самогоне и водке в интернете, которые были получены с помощью общедоступного инструмента Google Trends ${ }^{2}$. Данный алгоритм позволяет выбрать страну, регион, произвольный с 2004 г. период времени (дни, месяцы, годы) и задать поисковый запрос в виде слова или сочетания слов. В ответ на это Google Trends выдает результаты в виде числового ряда. Алгоритм Google Trends автоматически высчитывает долю поисковых запросов от всех запросов в Интернете и таким образом нормализует запросы во времени и делает их независимыми от изменений количества подключений в тот или иной период. Далее Google Trends определяет максимальное число поисковых запросов в избранном периоде и принимает его за $100 \%$; остальные точки этого периода автоматически пересчитываются в процентах к максимуму.

В качестве поисковых запросов использовали слова и словосочетания: «самогон» и «водку»+«водка купить». Ответ на слово «самогон» включает все словосочетания с этим словом (например, «самогонный аппарат» и «самогон рецепт»). Для настоящего

\footnotetext{
${ }^{1}$ URL: https://www.fedstat.ru/indicator/57614

${ }^{2}$ URL: https://trends.google.com
} 
исследования данные были представлены помесячно или подневно с января 2004 г. по февраль 2020 гг.

\section{РезУЛьтаты}

\section{А. Общцая смертность}

Ежедневные суммарные данные всех смертей в 2000-2017 гг. представлены на рисунке 1.

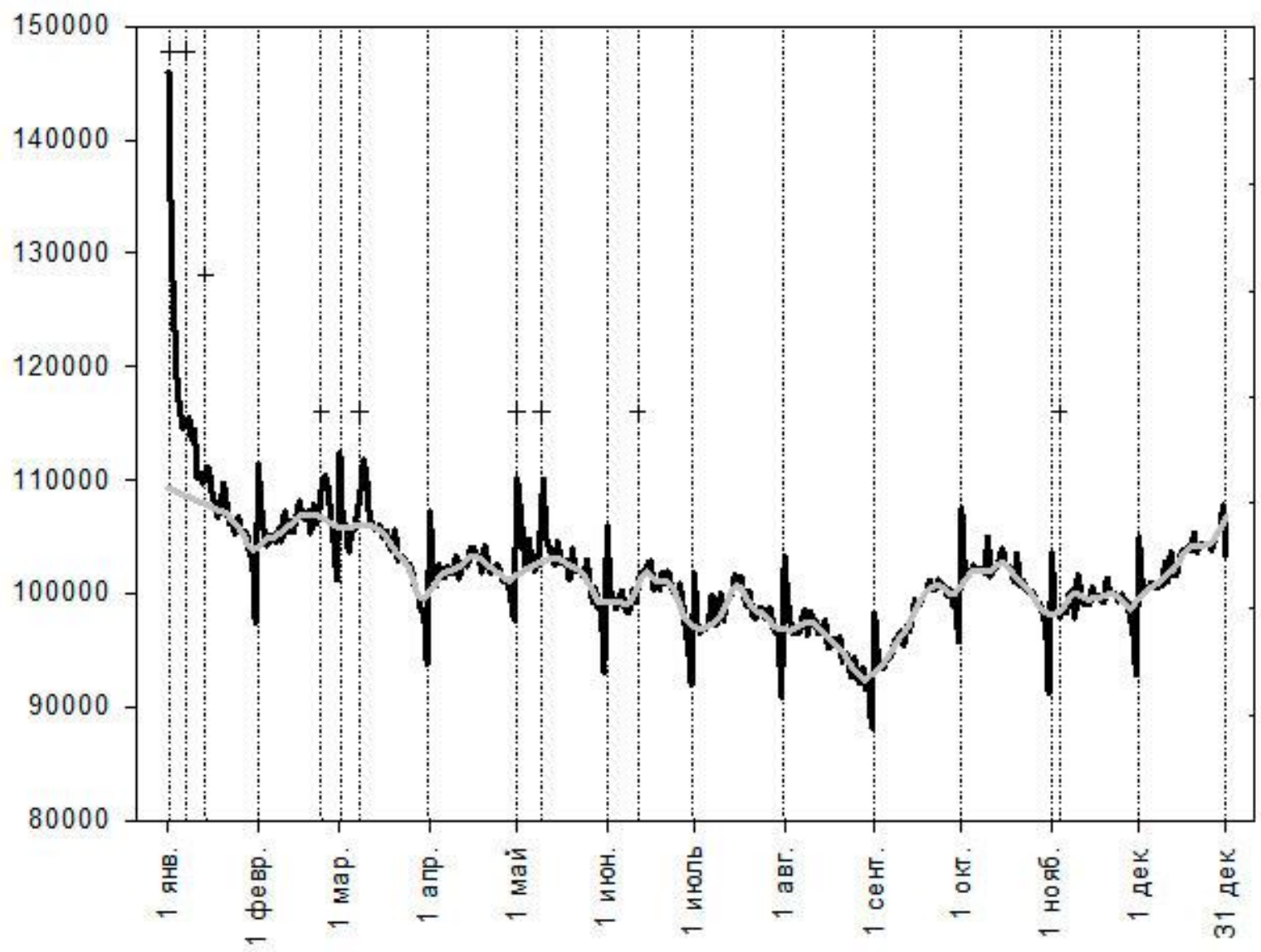

Рисунок 1. Распределение суммарного числа умерших в течении года за период 20002017 гг. в России

Серая линия - плавающуая средняя LOWESS для непраздничных дней, экстраполированная на праздничные дни. Вертикальный пунктир - первые числа месячев и дни праздников; крестиками последовательно обозначены: 1, 7 и 14 января, 23 февраля, 8 марта, 1 и 9 мая, 12 июня и 4 ноября.

Источник: Расчеты авторов.

Основной тренд смертности определяется проградиентным снижением смертей к сентябрю и возвратным ростом к декабрю. Этот тренд дополняется нерегулярными месячными колебаниями с максимальными значениями в летний период. На рисунке 1, кроме того, можно выделить ряд регулярных пиков, которые приходятся на первое число каждого месяца с февраля по декабрь. Каждому такому максимуму предшествует минимум в последнее число месяца. Вероятно, они являются артефактом в связи с произвольным переносом регистрации части смертей в последний день месяца на первое число 
следующего месяца. Нельзя исключить, что изменение учета происходит не в 2, а в 3 или 4 дня. Столь же значительного уменьшения смертей 31 декабря не наблюдалось (рисунок 1). Следует отметить, что пики в первых числах месяцев в последние 3 года выражены слабее (2015-2017 гг.). Сходное явление, но в недельном исполнении, наблюдалось в США и отмечено в работе 1999 г. (Phillips, Christenfeld, Ryan 1999: 93). В публикациях Д. Филлипса и соавторов 2004 и 2010 г., работавших по сходной тематике и со сходными задачами, этого не отмечалось (Phillips, Barker, Brewer 2010: 1463; Phillips et al. 2004: 3781). Кроме пиков такого технического свойства на рисунке 1 видны пики, соответствующие 1 января, 23 февраля, 8 марта и 9 мая. Можно заметить дополнительные пики 7, 14 и 20 января, которые накладываются на «хвост» пика 1 января, а также то, что пик 1 мая отличается продолжительностью от других максимумов в первых числах месяца.

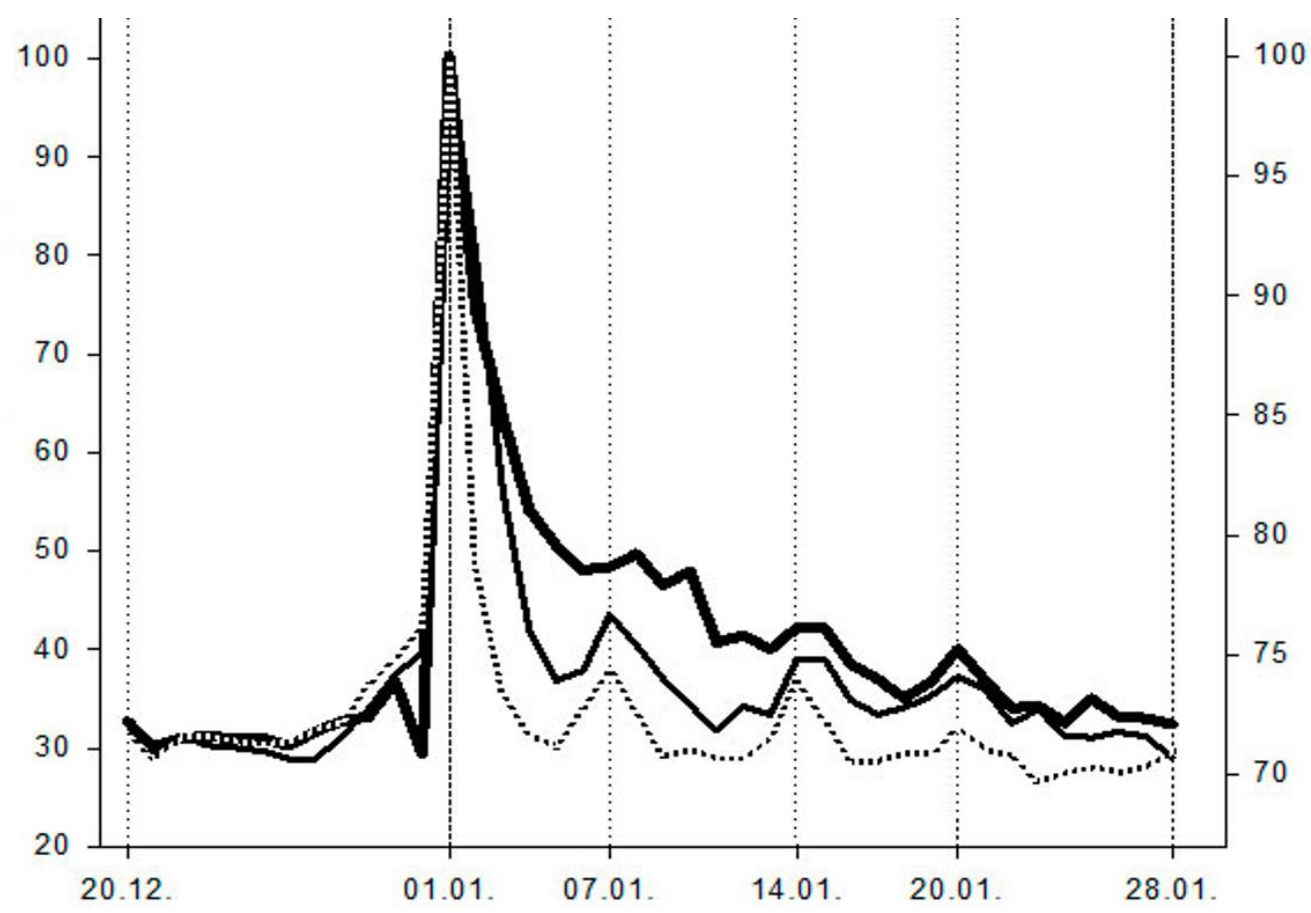

Рисунок 2. Отношение ежедневного числа смертей с 20 декабря по 28 января к максимальному уровню, фиксируемому 1 января (1 января = 100\%; показатели усреднены; 2000-2017 гг.).

Толстая линия - отношение ежедневного общего числа смертей $\kappa$ максимальному уровню, фиксируемому 1 января (ось справа), тонкая - при отравлении алкоголем, пунктир - убийства (ось слева).

Источник: Расчеты авторов; убийства - (Немцов 2019: 31).

Пик 1 января самый большой среди всех пиков в праздники (рисунок 1). Для расчета дополнительного числа смертей в связи с Новым годом и другими январскими праздниками отбирали дни с превышением доверительных интервалов плавающей средней LOWESS для непраздничных дней (серая линия на рисунке 1). Для оценки периода дополнительной смертности в праздники можно было выбрать 2 варианта: считать окончанием праздничного прироста смертей день, когда кривая смертности пересекает либо доверительный интервал 0,95, либо линию LOWESS. Выбран первый, более жесткий метод, в соответствие с чем учитывали потери с 1 по 14 с исключением 10-13 января. Во втором 
случае избыточные потери пришлось бы считать до 17 января без исключений 10-13 января. Динамика числа смертей в январе представлена на рисунке 2, оценка дополнительных избыточных смертей - в таблице 1.

В ноябре-декабре число смертей в целом увеличивается с некоторым замедлением после 20 декабря (рисунки 1, 2) и ростом после 28 декабря. Снижение на 106 смертей 31 декабря не выходит за пределы доверительного интервала LOWESS. Значимый прирост числа смертей наблюдался с 1 по 10 и 14-15 января и соответствует праздникам Нового года, Рождества и старого Нового года. Дополнительный пик 20 января вслед за праздником Богоявления/Водосвятия 19 января был незначим.

Таблица 1. Оценка избыточного числа смертей в связи с праздниками в январе в 2000-2017 гг. (пропуск 11-13 января - незначимый прирост)

\begin{tabular}{|c|c|c|c|c|c|c|c|c|c|c|c|c|}
\hline \multirow[b]{2}{*}{ Дата } & \multicolumn{12}{|c|}{ Число смертей в праздники } \\
\hline & 1 & 2 & 3 & 4 & 5 & 6 & 7 & 8 & 9 & 10 & 14 & 15 \\
\hline $\begin{array}{l}\text { Сумма потерь в } \\
\text { отдельные дни } \\
\text { (человек) }\end{array}$ & 35558 & 20153 & 13833 & 8208 & 6172 & 4789 & 5068 & 5957 & 4155 & 5102 & 2285 & 2360 \\
\hline Общая сумма & \multicolumn{12}{|c|}{113640} \\
\hline $\begin{array}{l}\text { Сумма потерь в } \\
\text { отдельные дни } \\
(\%)\end{array}$ & 31,3 & 17,7 & 12,2 & 7,2 & 5,4 & 4,2 & 4,5 & 5,2 & 3,7 & 4,5 & 2,0 & 2,1 \\
\hline
\end{tabular}

В 2000-2017 гг. число избыточных смертей в январские праздники составило 113,6 тыс. человек (таблица 1) или 6,3 тыс. в среднем в январские праздники с максимумом 1 января в 2 тыс. человек. Этот результат следует считать более точным по сравнению с тем, что было сделано ранее на основе месячных показателей (Немцов 2017b). Число умерших в праздничные дни в среднем на 14,0\% больше, чем в будни (смертность в будни рассчитывали на основе плавающей средней).

Избыточные потери в январе менялись год от года и в целом снижались по мере уменьшения потребления алкоголя. Так, в 2003 г. на высоте последнего пика смертности и потребления дополнительно произошло 17827 смертей, а в 2005 г. на фоне снижения этих показателей - 8513. Однако пик 1 января остается неизменным на всем протяжении исследования (рисунок 3), составляя 120-130\% от средней декабря. После 2012-2013 гг. снижение смертности после пика 1 января стало более пологим и достигало уровня декабря только в конце января; в некоторые годы это явление было выражено особенно резко (рисунок 3), но это не повлияло на общую оценку потерь - это новое явление до 2017 г. включительно отразилось в средних значениях. Попутно стоит обратить внимание на то, как в последние годы вырос пик 1 февраля.

Остальные 6 праздников, отмеченные крестами на рисунке 1, анализировали так же, как в случае январских праздников. Однако праздник 1 мая выпал из расчетов общей смертности из-за ошибок учета в первых числах месяца. В праздники 4 июня и 12 ноября роста смертности не обнаружили (рисунок 1). Значимые результаты представлены в таблице 2. 


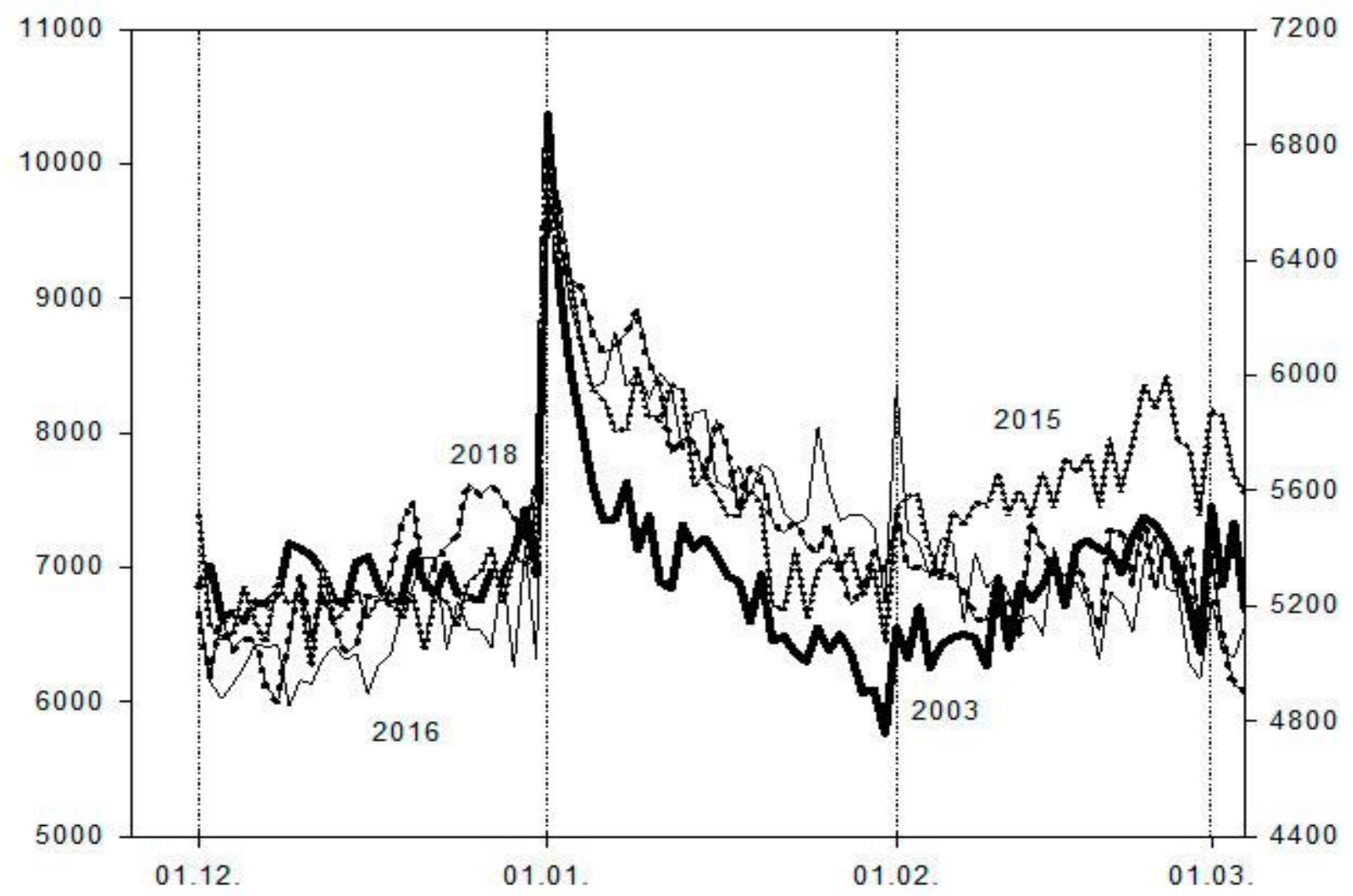

Рисунок 3. Динамика числа смертей в России в разные годы с 1 января по 1 марта

Максимумы 1 января 2015, 2016, 2018 г2. (тонкая и пунктирные линии - ось слева) приведень к максимуму 2003 года (толстая линия - ось справа).

Источник: Расчеты авторов.

Таблица 2. Оценка избыточного числа смертей в связи с праздниками в феврале, марте и мае (сумма за 2000-2017 гг.)

\begin{tabular}{|c|c|c|c|c|c|c|c|}
\hline \multirow{3}{*}{ Показатель } & \multicolumn{7}{|c|}{ Дни и месяцы праздников } \\
\hline & \multicolumn{2}{|c|}{ февраль } & \multicolumn{3}{|c|}{ март } & \multicolumn{2}{|c|}{ май } \\
\hline & 23 & 24 & 8 & 9 & 10 & 9 & 10 \\
\hline $\begin{array}{l}\text { Число избыточных смертей в } \\
\text { праздники }\end{array}$ & 4004 & 4275 & 3168 & 6306 & 5211 & 1691 & 6502 \\
\hline $\begin{array}{l}\text { Сумма по месяцам } \\
\text { Всего }\end{array}$ & \multicolumn{2}{|c|}{8279} & & \multicolumn{2}{|l|}{$\begin{array}{l}14685 \\
31157\end{array}$} & \multicolumn{2}{|c|}{8193} \\
\hline
\end{tabular}

Как видно, наибольшее число потерь сопряжено с праздником 8 марта, а суммарные потери трех праздников в 3,5 раза меньше январских. Таким образом, общее число избыточных смертей в связи с праздниками составило в 2000-2017 гг. 144797 или 8044 в год (таблица 1 и 2). 


\section{Б. Смерти при отравлении алкоголем}

В 2000-2017 гг. смерти при отравлении алкоголем составили 1,42\% от общего числа смертей. Как для общей смертности, так и для смертей при отравлении алкоголем характерно снижение в летние месяцы с минимумом в начале августе (рисунок 4). После этого начинается возвратный рост к декабрю. Кроме того, на рисунке выявляются ежемесячные колебания с максимумом в середине месяца, более отчетливые по сравнению с общей смертностью (рисунки 4 и 1). Примечательно, что пики конца-начала месяца отсутствуют.

На рисунке 4 видны пики в праздники: значимыми оказались 1, 7 и 14 января, 28 февраля, 8 марта, 1 и 9 мая. Праздничные пики выражены более четко в сравнении с общей смертностью (рисунок 1), они точно соответствуют пикам общей смертности, но короче последней (рисунок 2). Число смертельных отравлений в праздничные дни на $41,5 \%$ больше, чем в будни.

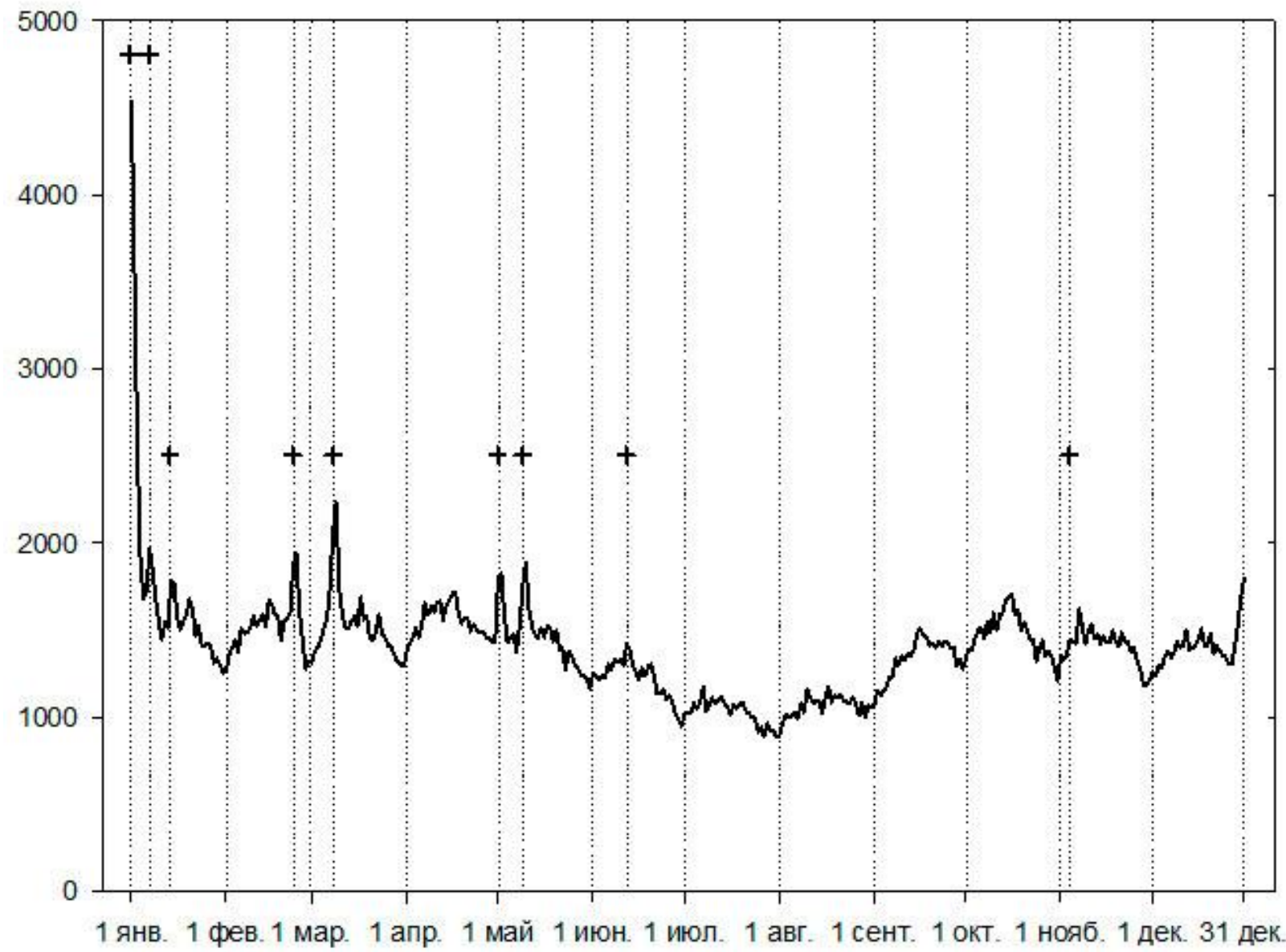

Рисунок 4. Распределение ежедневного числа смертей в течении года при отравлении алкоголем за период 2000-2017 гг. в России

Крестиками последовательно обозначены: 1, 7, 14 и 20 января, 23 февраля, 8 марта, 1 и 9 мая, 12 июня и 4 ноября.

Источник: Расчеты авторов. 
Рост отравлений начинается 28 декабря, как и убийств. Вероятно, так же начинается рост общей смертности, искаженный артефактом 31 декабря (рисунок 2). В январские праздники доля смертей при отравлении алкоголем возрастает в общей смертности более чем в 2 раза (с 1,42 до 3,53\%). Дополнительное число смертей при отравлении алкоголем суммарно в 2000-2017 гг. представлено в таблице 3 и составляет в целом 14682.

Таблица 3. Оценка избыточного числа смертей в связи с отравлениями алкоголем в праздники в 2000-2017 гг.; пропуск 10-13 января - незначимый прирост

\begin{tabular}{|c|c|c|c|c|c|c|c|c|c|c|c|}
\hline Месяц & \multicolumn{11}{|c|}{ январь } \\
\hline Даты & 1 & 2 & 3 & 4 & 5 & 6 & 7 & 8 & 9 & 14 & 15 \\
\hline $\begin{array}{l}\text { Избыточное } \\
\text { число смертей }\end{array}$ & 3236 & 2290 & 1207 & 577 & 349 & 379 & 622 & 490 & 315 & 393 & 380 \\
\hline Всего & \multicolumn{11}{|c|}{10238} \\
\hline$\%$ & 31,6 & 22,4 & 11,8 & 5,6 & 3,4 & 3,7 & 6,1 & 4,7 & 3,1 & 3,8 & 3,7 \\
\hline Месяц & \multicolumn{2}{|c|}{ февраль } & \multicolumn{2}{|c|}{ март } & \multicolumn{5}{|c|}{ май } & & \\
\hline Даты & 23 & 24 & 8 & 9 & 1 & 2 & 9 & 10 & 11 & & \\
\hline $\begin{array}{l}\text { Избыточное } \\
\text { число смертей }\end{array}$ & 381 & 452 & 590 & 755 & 457 & 485 & 434 & 573 & 317 & & \\
\hline Всего & \multirow{2}{*}{\multicolumn{2}{|c|}{833}} & \multicolumn{2}{|c|}{1345} & & & 2266 & & & & \\
\hline Сумма & & & & +444 & & & & & & & \\
\hline$\%$ & 45,7 & 54,3 & 35,9 & 64,1 & 20,2 & 21,4 & 19,2 & 25,3 & 14,0 & & \\
\hline
\end{tabular}

Представляет интерес соотношение избыточных смертей общих и при отравлении алкоголем (таблица 4). Это соотношение позволяет приблизительно оценить избыточную общую смертность 1 мая, которую не удалось определить напрямую из-за дефекта учета. Избыточная общая смертность в среднем больше отравлений в 9,6 раз. Можно предположить, что потери 1 мая составили 942 х 9,6=9043. Эта величина в сумме с общими избыточными смертями в остальные праздники составит $5,9 \%$, что близко к доле отравлений в их общей сумме (6,4\%). Из этого можно сделать предположение, что общая смертность в праздники 1 мая в 2000-2017 гг. суммарно была около 9 тыс. смертей.

Таблица 4. Соотношение избыточной общей смертности и при отравлениях алкоголем в праздники

\begin{tabular}{|c|c|c|c|c|}
\hline \multirow[b]{2}{*}{ Праздники } & \multicolumn{2}{|c|}{ Избыточное число смертей } & \multirow{2}{*}{$\begin{array}{c}\text { \% отравлений к } \\
\text { их сумме }\end{array}$} & \multirow{2}{*}{$\begin{array}{c}\text { Отношение } \\
\text { общего } \\
\text { количества к } \\
\text { отравлениям }\end{array}$} \\
\hline & $\begin{array}{c}\text { отравления } \\
\text { алкоголем }\end{array}$ & общее число & & \\
\hline 1 января & 10238 & 113640 & 69,7 & 11,1 \\
\hline 23 февраля & 830 & 8279 & 5,7 & 10,0 \\
\hline 8 марта & 1345 & 14685 & 9,2 & 10,9 \\
\hline 1 мая & 942 & - & 6,4 & - \\
\hline 9 мая & 1324 & 8193 & 9,0 & 6,2 \\
\hline Среднее & & & & 9,6 \\
\hline
\end{tabular}

\section{В. Смерти мужчин и женщцин}

Усредненные данные о смертях мужчин и женщин по раздельности в 2000-2017 гг. представлены на рисунке 5.

Главная особенность тренда смертей женщин - снижение к середине года с минимумом в августе-сентябре, тогда как у мужчин это особенность выражена слабее - они умирают в течение года более равномерно. С февраля по июль среднее число смертей у 
мужчин снизилось на 3,2\%, а у женщин - на 12,2\%. Соответственно в июле доля смертей мужчин увеличилась с 50,8 до 53,2\%.

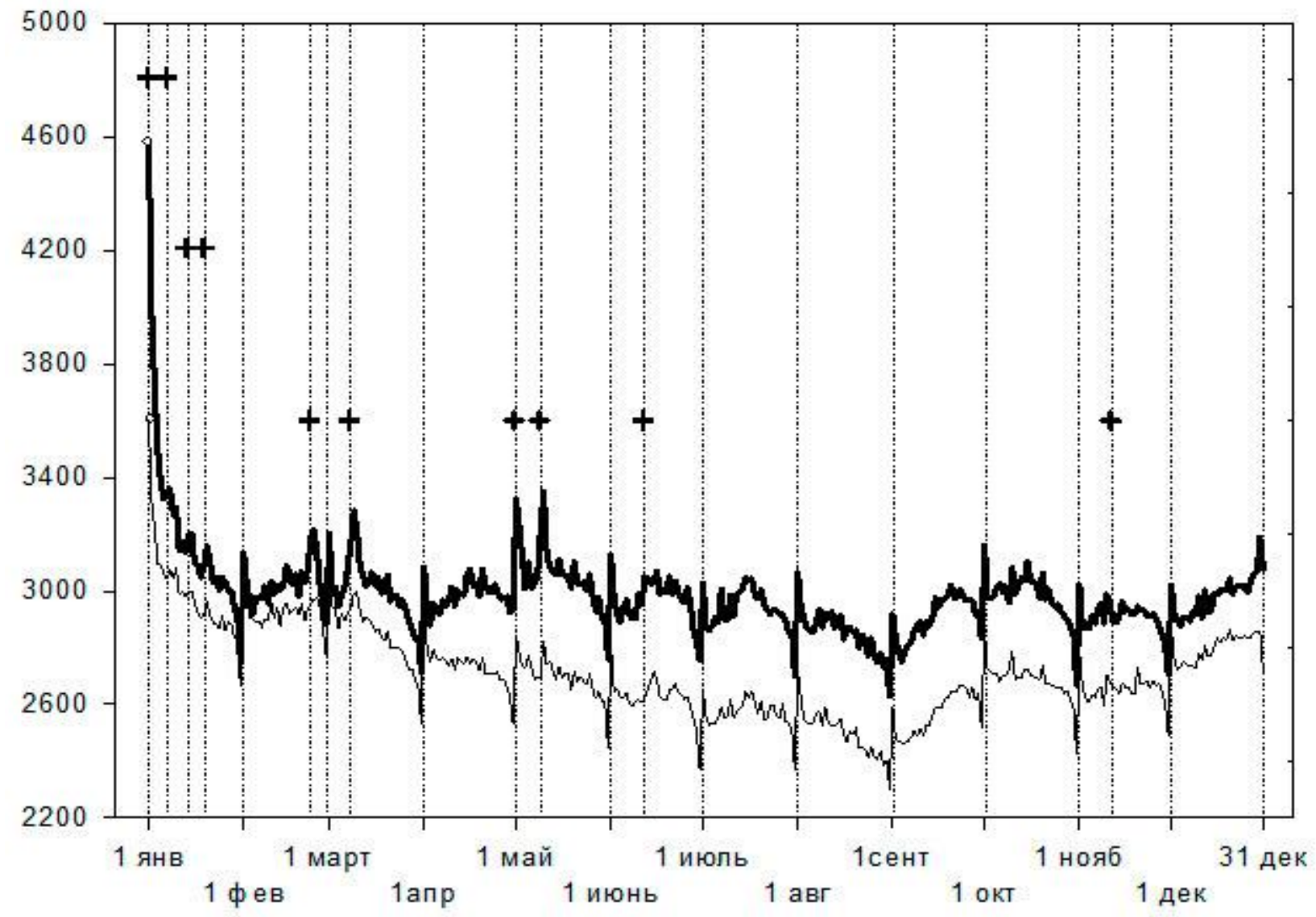

Рисунок 5. Распределение ежедневного числа смертей мужчин и женщин в течении года за период 2000-2017 гг. в России

\begin{abstract}
Мужчины - толстая линия, женщинь - тонкая линия. Кружками обозначень максимумь 1 января, крестиками - государственные и национальные праздники.
\end{abstract}

Источник: Расчеты авторов.

Артефакты последних и первых чисел месяца выражены одинаково, исключение составили 30 апреля и 31 декабря: у мужчин снижение отсутствовало.

Максимум смертей 1 января как у мужчин, так и у женщин, выражен значительно, но мужчин в этот день в абсолютном выражении умерло на 26,2\% больше, чем женщин (при условии, что общее число женщин в России в 2000-2016 гг. было на 10\% больше, относительный показатель различается еще больше); пики в остальные праздники у женщин значительно меньше, либо не выражены совсем. Детальный анализ смертности в январе показал, что новогодний прирост смертей мужчин растягивается до 24 января и составляет 6554 смертей. У женщин прирост смертей заканчивается 11 января и составляет 1550 смертей. Избыточные потери мужчин составили в январе 80,9\% от общих. Суммарное число избыточной смертности мужчин и женщин $(8,1$ тыс.) больше, чем общей $(8,0$ тыс.), что, скорее всего, связано с более детальным определением длительности периода потерь при оценке гендерных различий. 


\section{Г. Длительность праздников как фактор роста смертности в январе}

Среди поведенческих факторов роста смертности в январе часто называют большую, до 11 дней, длительность новогодне-рождественских праздников, объединивших Новый год, Рождество и старый Новый год. Увеличение продолжительности январских праздников произошло 1 января 2005 г. (Ф3-201 2004). А до этого срока новогодние и рождественские праздники были разделены двумя-тремя рабочими днями и в сумме составляли 4-5 дней. Можно определить влияние продолжительности праздников, сравнив 2 пятилетия, до и после утверждения Закона (ФЗ-201 2004) (рисунок 6).

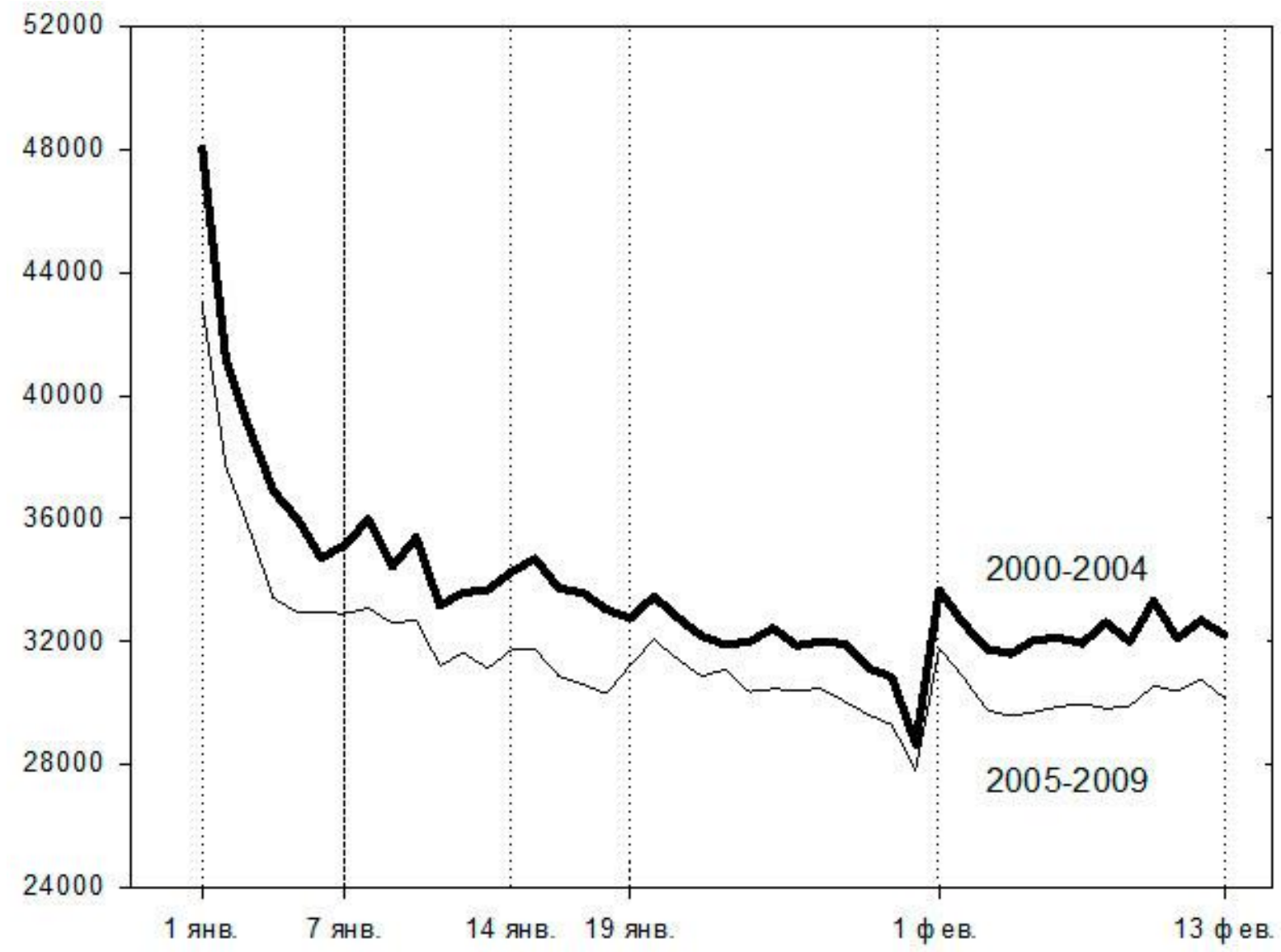

Рисунок 6. Распределение числа смертей между 1 января и 13 февраля в 2000-2004 и 2005-2009 гг.

Толстая линия -2000-2004 г2., тонкая линия - 2005-2009 г2. Вертикальный пунктир - государственные и национальные праздники, а также 1 февраля.

Источник: Расчеты авторов.

Как видно на рисунке 6, распределение смертей по годам различается количественно: в 2000-2004 гг. смертей было больше. Это связано с тем, что на этот период пришелся рост смертности, а на 2005-2009 гг. - ее снижение. Однако форма распределения 2005-2009 гг. практически дублирует распределение 2000-2004 гг. Следует отметить, что в 2004-2009 гг. дублируется не только распределение праздничных дней, но и артефакт начала-конца месяца (31 января-1 февраля). 


\section{Д. Потребление алкоголя}

Для оценки избыточных смертей в январские праздники важно исследовать характер потребления алкоголя в связи с праздником, однако для анализа доступны только легальные продажи, которые составляют большую часть потребления (около 70\%) ${ }^{3}$. Распределение месячных продаж главных по алкоголю напитков (водки и винной продукции) с января 2017 г. представлено на рисунке 7.

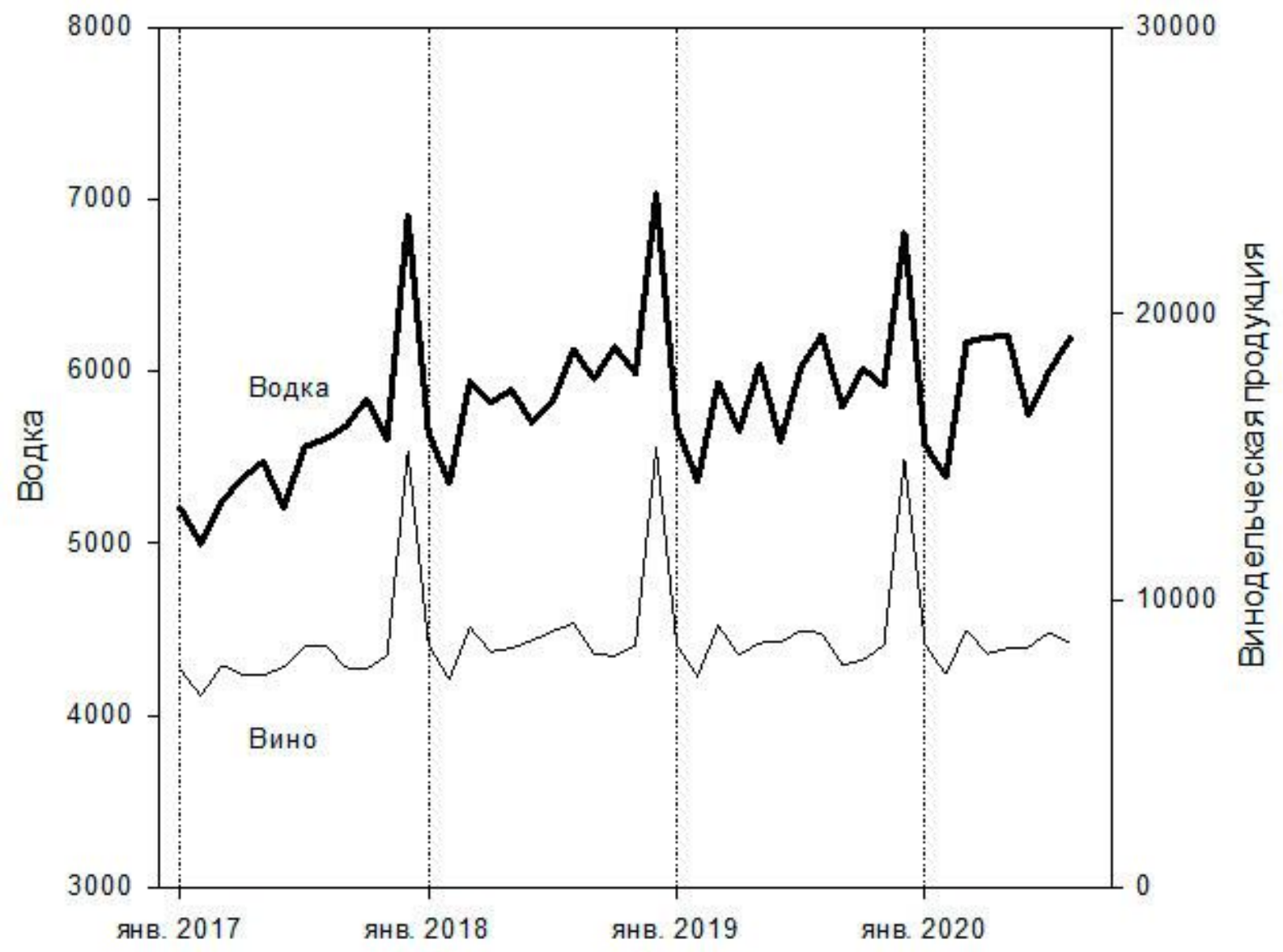

Рисунок 7. Распределение продаж водки и винодельческой продукции (вино) по месяцам с января 2017 г. по ноябрь 2020 г., тыс. декалитров в месяц

Источник: Данные Росстата РФ, расчеты авторов.

Более ранние данные не вполне пригодны для анализа в силу того, что менялась рубрикация винной продукции, вводилась ЕГАИС (Единая государственная автоматизированная информационная система), распространяясь на все большее число территорий и тем самым повышая точность учета продаж. Однако на рисунке 7 видно, что и до 2017 г., и после годовой максимум продаж приходится на декабрь каждого года.

\footnotetext{
${ }^{3}$ Министерство здравоохранения Российской Федерации. Приказ № 575 от 30 июля 2019 г. «Об утверждении методики оценки среднедушевого потребления алкоголя в Российской Федерации». Приложение к приказу.
} 
Представление о продаже нелегальной алкогольной продукции можно получить косвенно на основе популярности запросов в Интернете на доставку спиртных напитков (рисунок 8).

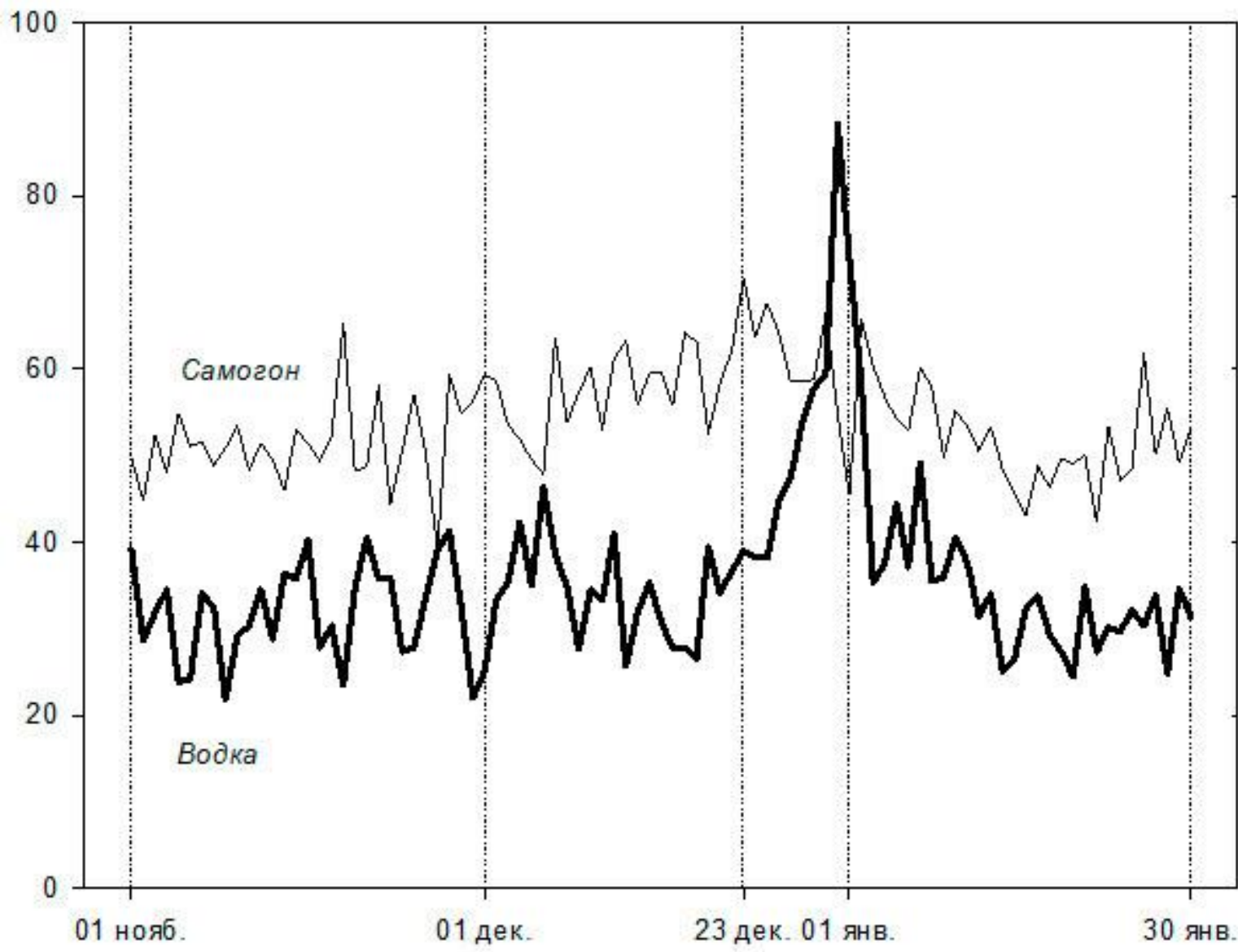

Рисунок 8. Отношение числа ежедневных запросов в Интернете на словосочетание «водка» + «водка купить» (водка) и «самогон» с 1 ноября по 31 января (среднее значение для 2007-2020 гг.), к максимуму

Источник: Данные Google Trends Pосстата РФ, расчеты авторов.

Запросы на самогон нарастают с мая по декабрь с максимумом 23 декабря, после чего начинается снижение числа запросов, особенно резкое 1 января. Запросы на водку поступали с небольшими колебаниями и довольно равномерно с февраля по 23 декабря, после чего начинался их резкий рост с максимумом 31 декабря и последующим еще более резким снижением 1-2 января.

\section{Е. Смерти в день рождения}

Празднование дня рождения по популярности сопоставимо с Новым годом. Однако в отличие от Нового года и других праздников день рождения рассредоточены в течение года, из-за чего потребовалась другая методика выявления связанной с ним смертности: совмещение дней рождения со 182 днями до и после него (рисунок 9). 


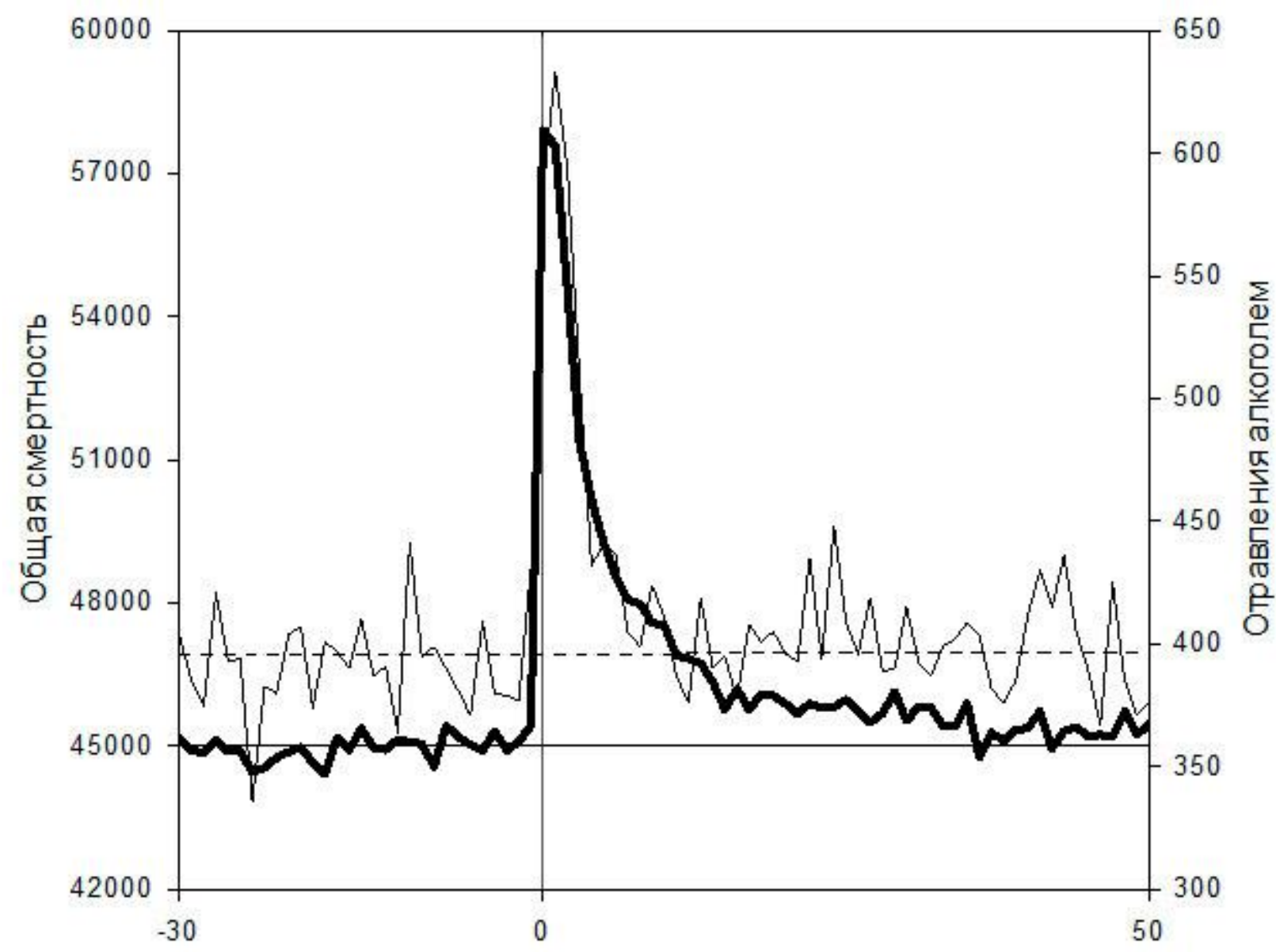

Рисунок 9. Распределение общего числа смертей (толстая линия - ось слева) и при отравлении алкоголем (тонкая линия - ось справа) за 30 дней до и 50 дней после дня рождения

Горизонтальные линии - регрессии дней вне дня рождения: прямая - общая смертность, пунктир отравления алкоголем.

Источник: Расчеты авторов.

На рисунке 9 видно, что в связи с днем рождения происходит резкий рост числа смертей с максимумом в день рождения и постепенным снижением смертности на протяжении 4 дней для отравлений и 22 дней для общей смертности (день пересечения доверительного интервала регрессии для непраздничных дней).

Таблица 5. Оценка избыточного числа смертей в связи с днем рождения в 2011-2019 гг.

\begin{tabular}{l|c|c|c|r|r}
\hline Смертность & Число дней & Среднее & Сумма & Минимум & Максимум \\
\hline Общая & 22 & 8665,1 & 77986 & 851 & 12867 \\
При отравлении алкоголем & 4 & 82,0 & 738 & 36 & 237 \\
\hline
\end{tabular}

За период 9 лет (2011-2019 гг.) избыточное число смертей составило 78,0 тыс., для отравлений алкоголем - 0,7 тыс. (таблица 5; в среднем 8,7 и 0,08 тыс. в год соответственно). Соотношение потерь общей смертности и отравлений в случае дней рождения описывается 
как 106:1, тогда как это соотношение в январские праздники составляет 11:1 при близком числе потерь общей смертности (8 и 9 тыс.).

\section{ОБСУЖДЕНИЕ РЕЗУЛЬТАТОВ}

Многократно была показана неравномерность распределения смертей в течение года с максимумом в январе, точнее, в новогодне-рождественские праздники. Если судить по числу смертей, можно считать, что в странах христианской культуры Рождество и/или Новый год являются главными праздниками года. Теперь к этим странам можно добавить Россию, где максимум смертей в течение года приходится на 1 января каждого года (рисунок 1). Избыточное число смертей в связи с январскими праздниками сохраняется в среднем до 15 января (таблица 1, рисунок 2): у мужчин до 22 января и у женщин до 11 января. За 18 лет с 2000 по 2017 г. дополнительно в этот период времени погибло 113,6 тыс. человек (таблица 1) или 6,3 тыс. в год в среднем, из которых 2 тыс. смертей приходятся на 1 января. Максимум избыточных смертей в январские праздники наблюдался в 2003 г. на максимуме общей смертности, когда избыточные смерти в январе составили 17,8 тыс. человек. В следующие годы вместе со снижением общей смертности и потребления алкоголя происходило уменьшение первоянварского пика, однако после 2012-2013 гг. снижение смертности со 2 января становилось более пологим (рисунок 3), увеличивая тем самым избыточные потери. Вероятно, это происходило за счет включения новых категорий патологии и/или новых возрастных групп, что еще предстоит исследовать.

Январские потери можно сложить с потерями в остальные праздники, получим избыточные праздничные потери в 2000-2017 гг., которые составили 144,8 тыс. человек или 8,0 тыс. смертей в год.

Смерть 113,6 тыс. человек за 18 лет - много это или мало? Ответить на вопрос поможет сравнение с населением большого города, такого, например, как Обнинск (117,4 тыс.; Калужская обл.) или Камышин (109,9 тыс., Волгоградская обл.). Иначе говоря, только январские потери за 18 лет сопоставимы с потерей населения большого города за тот же период. Количественную оценку можно произвести иначе, сравнив с потерями в других странах.

Самое подробное количественное исследование выполнено в США, где за 26 лет (1979-2004 гг.) избыточные потери в новогодне-рождественские праздники составили 42325 смертей или 1,6 тыс. в год в среднем (Phillips, Barker, Brewer 2010: 1463) против 8,0 тыс. в России - в 5 раз больше при двукратно меньшем населении страны. К расчетам для США требуется поправка: оценки сделаны для «естественных» причин (mortality from natural causes spikes), которые в этот период составляли 93\% всех смертей, а внешние причины смерти остались за пределами расчетов (Phillips, Barker, Brewer 2010: 1463).

За исключением смертей при отравлении алкоголем, диагностический состав смертей мы не исследовали, но в зарубежной литературе этот состав изучали подробно. Было показано, что в США существуют 2 максимума смертности, приходящиеся на 25-26 декабря (Рождество) и 1 января. Эти пики определялись на 93\% «естественными причинами», такими как заболевания системы кровообращения, новообразования, 
респираторные заболевания, эндокринные и метаболические заболевания, а также заболевания пищеварительной системы. И это касалось всех возрастных групп, кроме детей (Phillips, Barker, Brewer 2010: 1463). Среди внешних причин роста январской смертности в США и России назывались убийства в Новый год и/или Рождество (Bridges 2004: 723), самоубийства (Bergen, Hawton 2007: 855; Bridges 2004: 723) и злоупотребление алкоголем или наркотиками (Phillips, Barker, Brewer 2010: 1463).

Примечательно, что в западной литературе алкогольный фактор роста январской смертности отмечался, но, как правило, номинально. Он был специально исследован только в одной известной нам работе (Phillips, Barker, Brewer 2010: 1463), но и здесь он был невелик и выступал как равный в ряду других. В нашей работе исследование отравлений алкоголем предпринято для того, чтобы решить, как это было в России, в период исследования бывшей в группе лидеров потребления спиртных напитков. Среди всех патогенных факторов новогодних потерь в России алкогольный, вероятно, один из главных. Об этом свидетельствует выразительность новогодних пиков смертности, сходство последующей динамики общего числа смертей и при отравлении алкоголем (рисунок 2), максимумы которых приходятся на 1 января. Два вида смертности различаются по продолжительности их прироста в январе, и это, по-видимому, обусловлено различием танатогенеза: более кратким при отравлении и затяжным для общей смертности, в которой, как мы видели в США, преобладает соматическая патология (Phillips, Barker, Brewer 2010: 1463). Преобладала она и в России, в г. Кемерово (Барабаш, Алтарев, Фомина 2010: 35).

Самый короткий период избыточной смертности в праздники в случае убийств (Немцов 2019: 317), продолжительнее при отравлениях, самый длинный в случае общей смертности (рисунок 2). В таком же порядке, но по убыванию, располагаются эти виды избыточной смертности в новогодние праздники по сравнению с буднями: больше всего в праздники прирастают убийства (+206\%, т. е. в 3 раза (Немцов 2019: 317)); меньше отравления, еще меньше - общая смертность (соответственно $+41,5$ и $+14,0 \%$ ). В случае отравлений такой разрыв в будни и праздники, возможно, обусловлен тем, что в Новый год в тяжелое пьянство включаются люди с умеренной зависимостью или без нее, которых социальные ограничения удерживают от злоупотребления в будни. Связь убийств с употреблением алкоголя показана многократно (например, Ajdacic-Gross et al. 2012: 603; Phillips et al. 2004: 3781), эта связь обнаружена и в праздники (Phillips, Barker, Brewer 2010: 1463; Немцов 2019: 317), однако пока что не удается найти убедительное объяснение для России столь большого разрыва насилия в будни и праздники.

Значимость алкогольного фактора для общей смертности в России построена на сходстве с отравлениями по их динамике и по максимуму 1 января. Значение алкоголя для общей смертности в Новый год подчеркивает также заболеваемость алкогольными психозами, которые были исследованы в Москве и еще в шести крупных российских городах (Немцов 2017а: 76; Немцов, Изаровский, Сахаров 2014: 25). Отличие алкогольных психозов от алкогольной смертности состоит в том, что максимум психозов приходится на 7 января. Это можно объяснить тем, что всякому алкогольному психозу предшествует запой, длительность которого составляет в среднем (мода) 7 дней (Немцов, Лошаков 1997: 52). Из этого следует, что в случае психозов «алкогольный удар» также приходится на 1 января. 
Существует устойчивое представление, что тяжесть последствий новогодних праздников обусловлена их длительностью. Отсюда многочисленные предложения сократить длительность этих праздников. Но причина не в длительности: при сравнении двух периодов (2000-2004 и 2005-2009 гг.), между которыми продолжительность праздника увеличилась более чем в 2 раза, период избыточной смертности в первом и втором периоде была идентичной (рисунок 6). Их различие определяется тем, что в России в 2004 г., т. е. во втором периоде, началось снижение потребления алкоголя, которое продолжается по настоящее время (World health organization 2018: 90). Из этого следует важный вывод: ограничивать продажу крепких напитков следует в декабре, когда наблюдается годовой максимум продаж как легальных (рисунок 7), так и нелегальных (рисунок 8). Трудность решения этой проблемы даже для легального сектора очевидна: декабрь не только максимум продаж, но также максимум финансовых поступлений в бюджет с алкогольного рынка. Однако дело осложняется тем, что с 2016 г. формирование алкогольной политики передано Министерству финансов РФ. Главный и похоже единственный интерес этого министерства в сборе налогов на алкогольном рынке и борьба с нелегальным производством и продажей спиртного.

Избыточные смерти женщин в связи с Новым годом были в 4 раза меньше мужских, и заканчивался этот прирост женских смертей раньше. Меньше были выражены пики в другие праздники (рисунок 5). Это в который раз свидетельствует, что главный алкогольный урон несет мужское население. Интереснее другое: летнее снижение смертности происходит почти исключительно за счет женщин (рисунок 5). Однако связать это явление с особенностями алкоголизации мужчин не удалось: в случае алкогольных отравлений сезонные колебания выражены одинаково как свидетельство снижения потребления крепкого алкоголя в летнее время. А летнее снижение смертности женщин может объясняться большей чувствительностью женщин к погодным условиям в зимнее время (Murphy, Luy, Torrisi 2019).

Многогодичный тренд новогоднего прироста в целом соответствует тренду снижения потребления алкоголя, которое началось в 2004 г. (World health organization 2018: 90). Отклонение от этого тренда произошло в 2013-2014 гг., после чего снижение смертности в январе замедлилось на фоне продолжающегося снижения смертности в остальные месяцы года. Объяснить этот феномен можно тем, что в это время расширился период избыточной смертности почти до конца января (рисунок 3). Можно предположить, что это обусловлено включением в смертность новых групп населения (по возрасту и/или по причинам). Решить это может только специальное исследование.

Неожиданными явились результаты исследования дней рождения: связанные с этим потери оказались почти в 2 раза больше январских (8,0 тыс. против 6,0 тыс. в год), больше оказался период потерь (22 дня против 15). При этом в январе не 1, а 3 праздника. Примечательно, что в случае дней рождения общая смертность резко превалировала над отравлениями алкоголем (отношение 106:1) в сравнении с тем, что было в январе (11:1). Возможно, особенность этого праздника определяется большим участием пожилых людей и/или меньшим участием тяжелых потребителей алкоголя, для которых «каждый день праздник». Возможно, что и для этой когорты людей новогодний праздник более значим, чем день рождения: за 20 дней до Нового года начинается снижение заболеваемости 
алкогольными психозами с минимумом 1 января (Немцов 2017b: 76), а снижение смертности при отравлениях алкоголем перед днем рождения не выражено (рисунок 9).

Возникает вопрос, почему в России и других странах новогодне-рождественский праздник и день рождения выделяются особой тяжестью последствий, вплоть до смертельных? Можно сказать более широко - выделяется особым стилем поведения («В Рождество все немного волхвы» И.Бродский). Ни один другой праздник в России и в западных странах не предваряется таким предпраздничным ажиотажем и перемещением людей. Популяционно наблюдать это перед днем рождения трудно из-за рассредоточения этих дней в году. Однако в ожидании 1 января даже больные алкоголизмом снижают потребление спиртного, начиная с середины декабря, в результате чего минимум заболеваемости алкогольными психозами в праздники приходится на 1 января (Немцов 2017b: 76).

Тут следует сказать, что структурирование времени - естественная потребность, и эта потребность реализуется, в частности, выбором опорной точки. В «бытовом времени» одной из таких точек становится праздник (Воловикова, Тихомирова, Борисова 2003). Сопровождающие праздник обряды, в широком смысле слова, усиливают значение праздника (Шнейдер 2019). У праздника и его обрядности есть и другие функции, но почему среди праздников особая роль выпадает на долю Нового года, дня рождения и/или Рождества?

Представляется, что в основе этого феномена лежат традиции, сформированные на базе пережитков языческой психологии, которые в последние 3-4 десятилетия в России и мире отмечены расширением вплоть до появления неоязычества как религиозной практики (Крутоус 2005: 90). В бытовом и широком проявлении языческой психологии мало религиозности, но больше традиции, однако вера в приметы и сглаз все еще нередкое явление, а верность амулетам определяется также их свойством языческого оберега. Но особенно ярко языческая часть психологии современного человека выявляет себя на подходе к Рождеству или 1 января. Тому свидетельство широкое распространение новогодне-рождественской «обрядовости» в виде восточной символики и фетишизации праздника. Оказывается, в 2021 г. мы вступили в год металлического быка и его фарфоровые и другие изображения охотно раскупались перед Новым годом в сувенирных киосках. Языческое мироощущение остро проявляется не только перед 1 января, но и в день рождения. Определяется это скорее всего тем, что это рубежные даты, начало нового года или нового жизненного цикла, а цикличность превращений - важный элемент языческого миропонимания. Вторая важная черта язычества - воздаяние ради будущего благополучия. В этом контексте застолье и спиртное принимают еще одно свойство - ритуальное: «Как в Новый год гульнём, так весь год проживём» (цитата).

Важно отметить устойчивость приращения смертности в связи с рубежными праздниками как в США, так и в России. В США этот феномен наблюдался во время всего исследования, т. е. в течение 26 лет (1979-2004 гг.) (Phillips et al. 2004: 3781), а в России по меньшей мере с 1956 г., когда начался оперативный учет месячных показателей смертности. Различие двух стран определялось не только количественно, но и тем, что главные праздничные потери население США несло в Рождество, а в России - 1 января. 
И в том, и в другом случае пик годовой смертности приходится на эти дни. Для США называлось несколько причин новогодне-рождественских потерь, в том числе, алкогольная (Phillips et al. 2004: 3781). В отличие от этого в России, по-видимому, доминирует алкогольный фактор среди других, которые еще предстоит исследовать.

Пришла пора осторожно и без пафоса сопоставить такие явления, как радость, которую приносит новогодний праздник, и человеческие потери в это время и на этой основе определить приемлемость тех или других мероприятий по снижению урона. Главное в этом - информирование населения о возможных последствиях опасного для жизни и здоровья поведения в праздники. Представляется, что информационная политика должна быть дополнена снижением доступности крепкого алкоголя для наших граждан в связи с Новым годом. Делать это надо в декабре, особенно в его последнюю неделю, когда наблюдается годовой максимум продаж алкогольных напитков, в первую очередь крепких. Такой заслон может быть сделан в виде ценовой политики и/или нормирования продаж, и/или ограничения времени торговли спиртным.

Рост смертности в Новый год только вершина айсберга, гораздо шире представлена заболеваемость, которую еще предстоит исследовать, а в связи с этим требуется также специально готовить службы здравоохранения к этой дате. 19 ноября 2020 г. министр здравоохранения М.А. Мурашко на селекторном совещании уже предупреждал руководителей регионов о традиционном росте нагрузки в период новогодних праздников 4 .

Естественно, что такая работа не должна быть одноразовой и ограничиваться короткой предновогодней порой. Необходимо также склонить Министерство финансов к поддержке ограничений торговли алкогольной продукцией перед Новым годом.

\section{ОГРАНИЧЕНИЕ ИССЛЕДОВАНИЯ}

В отличие от общей идеи статьи к расчетам в ней следует относиться сдержанно. Это определяется тем, что они зависят от нескольких привходящих обстоятельств. Первым надо назвать опору расчетов на LOWESS. Этот метод имеет много преимуществ перед простой плавающей средней и другими еe видами, поскольку не требует предварительного определения формы кривой. Ho LOWESS определяется исходным выбором параметров оценивания. Трудно сказать, увеличивает или занижает это результаты расчетов, но и в том, и в другом случае ошибка невелика.

Второе ограничение, как уже отмечалось выше, связано с интерпретацией избыточной общей смертности как алкогольной на основании сходства динамики общей и алкогольной смертности. Правильнее было бы сопоставить числа умерших с алкоголем в крови до и после праздников, однако эти данные рассредоточены в локальных бюро судмедэкспертизы, но и там они представлены в суммарном, годовом виде, а для нашей задачи требуется их детальное распределение. Однако и в этом случае возможно только выборочное исследование: 35,4 млн случаев охватить такой работой пока что невозможно.

\footnotetext{
${ }^{4}$ URL: https://vrachirf.ru/company-announce-single/81862
} 
Третье ограничение связано с артефактами регистрации общей смертности в последние и первые дни месяца, которые исключались из расчетов. Это же заставило исключить смерти в связи с праздником 1 мая, а это искусственно снизило реальный урон в праздники. Артефакт, по-видимому, связан с ошибками или с фальсификацией первичного учета даты смертей. Это явление не воспроизводится при отравлениях алкоголем (рисунок 4) и убийствах (Немцов 2019: 31). Последние 2 вида смертности несут социально значимую информацию и поэтому находятся под особым контролем, не допускающим фальсификации даты смерти.

Есть и четвертое ограничение. Главный праздничный урон наблюдается в январе, самом холодном месяце года. Можно думать, что этот урон зависит от погодных условий в виде гриппа, ОРВИ и пневмонии. Вполне исключить этот фактор нельзя, но представить, что простудные заболевания естественным образом подверстываются к 1 января, тоже невозможно.

Из практики мы знаем, что празднование дня рождения, а значит и фатальные последствия, могут быть отложены на несколько дней, но, как правило, не больше чем на неделю. Если бы это явление было частым и распределялось случайным образом, т. е. в соответствие с нормальным или другим распределением, мы имели бы дополнительный пик или «ступеньку» смертности на нисходящей ветви после максимума. Но это не выявляется на рисунке 9, а это значит, что явление это нечастое и ошибка, которую вносят отложенные празднования, невелика.

Более определенно можно сказать, что результаты праздничных потерь в настоящей работе несколько занижены. Во-первых, это определяется исключением из расчетов праздников 1 мая, которые по косвенным данным могут составить около 9 тыс. человек за 18 лет. Второе, что могло занизить результаты, - это определение окончания приращения смертей в праздники по доверительному интервалу, а не по LOWESS. Из этого следует, что полученные в работе количественные оценки праздничных потерь следует интерпретировать как «не ниже чем».

\section{БЛАГОДАРНОСТИ}

Евгению Михайловичу Андрееву (Международная лаборатория исследований населения и здоровья НИУ ВШЭ) за безотказную помощь в работе.

\section{ЛИТЕРАТУРА}

Барабаш О.Л., Алтарев С.С., Фомина Н.В. (2010). Неблагоприятное влияние периода новогодних праздников на показатели общей и кардиоваскулярной смертности. Кардиология, 50(11), 35-39.

Воловикова М.И., Тихомирова С.В., Борисова А.М. (2003). Психология и праздник: Праздник в жизни человека. М.: ПЕР СЭ.

Жаксымбаев М. Динамика смертности от убийств в России. Демоскоn Weekly, 535-536. URL: http://www.demoscope.ru/weekly/2012/0535/analit09.php 
Крутоус В.П. (2005). Новоязычество в контексте культурного кризиса XX - начала XXI века. Традиционная культура: науч. альм., 2, 90-98.

Немцов А.В. (2017а). Праздник - фактор риска алкогольных психозов. Bonpocы наркологии, 10, 76-88.

Немцов А.В. (2017b). Смерти в январе - Россия: 2004-2016. Электронный научныий журнал «Социальные аспекты здоровья населения», 58(6). DOI: https://doi.org/10.21045/2071-5021-2017-58-6-2

Немцов А.В. (2019). Алкогольная составляющая убийств в праздники, Россия, 2000-2017 гг. Вопросы наркологии,176(5), 31-44. DOI: https://doi.org/10.47877/02340623_2019_5_31

Немцов А.В., Изаровский Б.В., Сахаров А.В. (2014). Годичный тренд алкогольных отравлений и психозов. Наркология, 1, 25-29. URL: http://mniiprepo.ru/uploads/1410778899.pdf

Немцов А.В., Лошаков Е.С. (1997). Краткая хронология алкогольных психозов. Социальная и клиническая психиатрия, 7(1), 52-61.

Шнейдер Л.Б. (2019). Психология идентичности. 2-е изд., пер. и доп. М.: Издательство Юрайт.

Abel E., Kruger M. (2009). Mortality Salience of Birthdays on Day of Death in the Major Leagues. Death Studies, 33(2), 175-184. DOI: https://doi.org/10.1080/07481180802138936

Ajdacic-Gross V., Knopfli D., Landolt K. et al. (2012). Death has a preference for birthdays - an analysis of death time series. Annals of Epidemiology, 22(8), 603-606. DOI: https://doi.org/10.1016/j.annepidem.2012.04.016

Alderson M. (1975). Relationship between month of birth and month of death in the elderly. British Journal of Preventive \& Social Medicine, 29(3), 151-156. DOI: https://doi.org/10.1136/jech.29.3.151

Bergen H., Hawton K. (2007). Variation in deliberate self-harm around Christmas and New Year. Social Science \& Medicine, 65(5), 855-867. DOI: https://doi.org/10.1016/j.socscimed.2007.04.004

Bovet J., Spagnoli J., Sudan C. (1997). Mortalité et anniversaire de naissance. Soz Präventivmed, 42(3), 155-161. DOI: https://doi.org/10.1007/BF01300566

Bridges F. (2004). Rates of homicide and suicide on major national holidays. Psychological Reports, 94(2), 723-724. DOI: https://doi.org/10.2466/pr0.94.2.723-724

Cleveland W., Devlin S. (1988). Locally Weighted Regression: An Approach to Regression Analysis by Local Fitting. Journal of the American Statistical Association, 83(403), 596-610. DOI: https://doi.org/10.2307/2289282

Doblhammer G. (1999). Longevity and month of birth: Evidence from Austria and Denmark. Demographic Research, 1(3), 1-22. DOI: https://doi.org/10.4054/DemRes.1999.1.3

Kloner R., Poole W., Perritt R. (1999). When throughout the year is coronary death most likely to occur? A 12 year population based analysis of more than 220000 cases. Circulation, 100(15), 1630-1634. DOI: https://doi.org/10.1161/01.cir.100.15.1630

Knight J., Schilling C., Barnett A. et al. (2016). Revisiting the "Christmas Holiday Effect" in the Southern Hemisphere. Journal of the American Heart Association, 5(12), e005098. DOI: https://doi.org/10.1161/JAHA.116.005098 
Medenwald D., Kuss O. (2014). Deaths and major biographical events: a study of all cancer deaths in Germany from 1995 to 2009. BMJ Open, 4(4), e004423. DOI: https://doi.org/10.1136/bmjopen-2013-004423

Milne E. (2005). Mortality spike at New Year but not Christmas in North East England. European Journal of Epidemiology, 20(10), 849-854. DOI: https://doi.org/10.1007/s10654005-2147-8

Motohashi Y. (2012). Suicide in Japan. The Lancet, 9823, 1282-1283. DOI: https://doi.org/10.1016/S0140-6736(11)61130-6

Murphy M., Luy M., Torrisi O. (2019). Mortality change in the United Kingdom and Europe. London, Social Policy Working Paper. Working Paper Series November 11-19. URL: https://www.lse.ac.uk/social-policy/Assets/Documents/PDF/working-paper-series/11-19Mike-Murphy.pdf

Peña P. (2015). A not so happy day after all: Excess death rates on birthdays in the U.S. Social Science \& Medicine, 126, 59-66. DOI: https://doi.org/10.1016/j.socscimed.2014.12.014

Phillips D., Barker G., Brewer K. (2010). Christmas and New Year as risk factors for death. Social Science \& Medicine, 71(8), 1463-1471. DOI: https://doi.org/10.1016/j.socscimed.2010.07.024

Phillips D., Christenfeld N., Ryan N. (1999). An increase in the number of deaths in the united states in the first week of the month an association with substance abuse and other causes of death. The New England Journal of Medicine, 341, 93-98. DOI: https://doi.org/10.1056/NEJM199907083410206

Phillips D., Jason R., Abramson I., Phillips R. (2004). Cardiac mortality is higher around Christmas and New Year's than at any other time the holidays as a risk factor for death. Circulation, 110(25), 3781-3788. DOI: https://doi.org/10.1161/01.cir.0000151424.02045.f7

Phillips D., Van Voorhees C., Todd R. (1992). The Birthday: Lifeline or Deadline? Psychosomatic Medicine, 54(5), 532-542. DOI: https://doi.org/10.1097/00006842199209000-00001

Reulbach U., Biermann T., Markovic K., Bleich S. (2007). The myth of the birthday blues: a population-based study about the association between birthday and suicide. Comprehensive Psychiatry, 48(6), 554-557. DOI: https://doi.org/10.1016/j.comppsych.2007.06.006

Stickley A., Sheng Ng C., Inoue Y., Yazawa A., Koyanagi A., Kodaka M., DeVylder J., Watanabe Ch (2016). Birthdays are associated with an increased risk of suicide in Japan: Evidence from 27,007 deaths in Tokyo in 2001-2010. Journal of Affective Disorders, 200, 259-265. DOI: https://doi.org/10.1016/j.jad.2016.04.028

Vaiserman A., Grigoryev P., Belaya I., Voitenko V. (2003). Variation of mortality rate during the individual annual cycle. Biogerontology, 4(4), 221-225. DOI: https://doi.org/10.1023/A:1025168932058

Williams A., While D., Windfuhr K., Bickley H., Hunt I.M., Shaw J., Appleby L., Kapur N. (2011). Birthday Blues, Examining the Association Between Birthday and Suicide in a National Sample. Crisis, 32, 134-142. DOI: https://doi.org/10.1027/0227-5910/a000067

World health organization (2018). Global status report on alcohol and health 2018. Retrieved from https://www.who.int/publications/i/item/9789241565639

Zubaid M., Thalib L., Suresh C.G. (2006). Incidence of acute myocardial infarction during Islamic holiday seasons. European Journal of Epidemiology, 21(3), 191-195. DOI: https://doi.org/10.1007/s10654-006-0008-8 


\title{
EXCESS MORTALITY IN RUSSIA ON HOLIDAYS
}

\author{
ALEXANDER NEMTSOV, ANATOLY SimONOV, \\ TIMUR FATTAKHOV, ROMAN GRIDIN
}

\begin{abstract}
Formulation of the problem. It is known that holidays are accompanied by an increase in morbidity and mortality. The aim of this study was to summarize the experience of previous studies examining the relationship between national holidays and the time of death, as well as to analyze the Russian characteristics of mortality during holidays. The article poses the following questions: 1) Is the risk of dying on holidays increasing in Russia? 2) If so, on which ones? 3) Is this related to alcohol abuse? 4) To what extent are men and women involved? 5) What is the estimate of excess deaths on holidays?
\end{abstract}

\begin{abstract}
Methods. The study used daily data on the number of deaths in Russia from all causes and from alcohol poisoning, disaggregated by sex for 2000-2017. In total, 35.4 million people died during the period under review. We studied 9 public holidays in Russia. The LOWESS moving average, calculated for non-holidays and extrapolated to holidays, was taken as zero. We took into account holidays that exceeded the LOWESS confidence interval. To estimate losses on a birthday, linear regression and its confidence interval were taken as zero. We used data from Rosstat and Google Trends to indirectly estimate legal and illegal alcohol consumption as well.
\end{abstract}

Results. Five out of nine public holidays in Russia are accompanied by an increase in the number of deaths. The greatest increase is observed in connection with the New Year on January 1-15. At this time, the excess number of deaths amounted to 113.6 thousand people over 18 years, or 6.3 thousand people per year, with a maximum on January 1 (2.0 thousand per day). This is $14.0 \%$ more deaths than on weekdays. The excess number of deaths on the holidays on February 23, March 8 and May 9 amounted to 1.7 thousand per year. $80.9 \%$ of excess deaths in January are of men. The all-cause mortality and mortality from alcohol poisoning coincides with the maximum on January 1. After 2005, when the duration of the New Year holidays increased, the maximum on January 1 and the subsequent dynamics of mortality did not change. The annual maximum sales of alcoholic beverages are in December. Birthdays are also accompanied by an increase in total mortality by 9.1 thousand per year, and this is also associated with alcoholism.

Conclusion. In Russia, on holidays, mainly on New Year's and birthdays, there is a significant increase in mortality, which is mainly due to alcohol abuse and does not depend on the duration of the holidays in January. This damage can be reduced by a decrease in the availability of strong alcohol, the maximum sales of which occur in December.

Key words: holidays, birthday, mortality, excessive mortality, alcohol poisoning, Russia, men, women.

AleXander V. Nemtsov (nemtsov33@gmail.com), NAtional Narcology Center, Russia.

Anatoly N. Simonov (danatoly.simonov@psychiatry.ru), Mental HeAlth Research Center, Russia.

Timur A. Fattakhov (timur300385@mail.ru), NATional Research University Higher School of Economics, RUSSIA.

Roman V. Gridin (rvgridin@gmail.com), Consumer Market DeVElopment Center, SKOLKOVO Business SCHOOL, RUSSIA.

IN THE PAPER WE USED THE RESULTS OBTAINED UNDER THE PROGRAM OF BASIC RESEARCHES BY HIGHER SCHOOL OF ECONOMICS

DATE RECEIVED : DECEMBER 2020. 


\section{REFERENCES}

Abel E., Kruger M. (2009). Mortality Salience of Birthdays on Day of Death in the Major Leagues. Death Studies, 33(2), 175-184. DOI: https://doi.org/10.1080/07481180802138936

Ajdacic-Gross V., Knopfli D., Landolt K. et al. (2012). Death has a preference for birthdays - an analysis of death time series. Annals of Epidemiology, 22(8), 603-606. DOI: 10.1016/j.annepidem.2012.04.016.

Alderson M. (1975). Relationship between month of birth and month of death in the elderly. British Journal of Preventive \& Social Medicine, 29(3), 151-156. DOI: https://doi.org/10.1136/jech.29.3.151

Barabash O.L., Altarev S.S., Fomina N.V. (2010). Unfavorable effect of the period of new year holidays on total and cardiovascular mortality. Kardiologiia, 50(11), 35-39. (In Russ.). URL: https://pubmed.ncbi.nlm.nih.gov/21526562/

Bergen H., Hawton K. (2007). Variation in deliberate self-harm around Christmas and New Year. Social Science \& Medicine, 65(5), 855-867. DOI: https://doi.org/10.1016/j.socscimed.2007.04.004

Bovet J., Spagnoli J., Sudan C. (1997). Mortalité et anniversaire de naissance. Soz Präventivmed, 42(3), 155-161. DOI: https://doi.org/10.1007/BF01300566

Bridges F. (2004). Rates of homicide and suicide on major national holidays. Psychological Reports, 94(2), 723-724. DOI: https://doi.org/10.2466/pr0.94.2.723-724

Cleveland W., Devlin S. (1988). Locally Weighted Regression: An Approach to Regression Analysis by Local Fitting. Journal of the American Statistical Association, 83(403), 596-610. DOI: https://doi.org/10.2307/2289282

Doblhammer G. (1999). Longevity and month of birth: Evidence from Austria and Denmark. Demographic Research, 1 (3), 1-22. DOI: https://doi.org/10.4054/DemRes.1999.1.3

Kloner R., Poole W., Perritt R. (1999). When throughout the year is coronary death most likely to occur? A 12 year population based analysis of more than 220000 cases. Circulation, 100(15), 1630-1634. DOI: https://doi.org/10.1161/01.cir.100.15.1630

Knight J., Schilling C., Barnett A. et al. (2016). Revisiting the "Christmas Holiday Effect" in the Southern Hemisphere. Journal of the American Heart Association, 5(12), e005098. DOI: https://doi.org/10.1161/JAHA.116.005098.

Krutous V.P. (2005). Novoyazychestvo v kontekste kul'turnogo krizisa XX - nachala XXI veka. Traditsionnaya kul'tura: nauch. al'm. [Traditional culture: scientific almanac], 2, 90-98. (In Russ.)

Medenwald D., Kuss O. (2014). Deaths and major biographical events: a study of all cancer deaths in Germany from 1995 to 2009. BMJ Open, 4(4), e004423. DOI: https://doi.org/10.1136/bmjopen-2013-004423

Milne E. (2005). Mortality spike at New Year but not Christmas in North East England. European Journal of Epidemiology, 20(10), 849-854. DOI: https://doi.org/10.1007/s10654005-2147-8

Motohashi Y. (2012). Suicide in Japan. The Lancet, 9823, 1282-1283. DOI: https://doi.org/10.1016/S0140-6736(11)61130-6

Murphy M., Luy M., Torrisi O. (2019). Mortality change in the United Kingdom and Europe. London, Social Policy Working Paper. Working Paper Series November 11-19. URL: 
https://www.lse.ac.uk/social-policy/Assets/Documents/PDF/working-paper-series/11-19Mike-Murphy.pdf

Nemtsov A.V. (2017a). Prazdnik - faktor riska alkogol'nykh psikhozov [Holiday is a risk factor for alcoholic psychoses]. Journal of addiction problems, 10, 76-88. (In Russ.)

Nemtsov A.V. (2017b). January deaths in Russia, 2004-2016. Electronic scientific journal "Social Aspects of Population Health", 58(6). (In Russ.) DOI: https://doi.org/10.21045/20715021-2017-58-6-2

Nemtsov A.V. (2019). Alcoholic component of holiday homicides, Russia, 2000-2017. Journal of addiction problems, 176(5), 31-44. (In Russ.) DOI: https://doi.org/10.47877/02340623_2019_5_31

Nemtsov A.V., Izarovskiy B.V., Sakharov A.V. (2014). One-year trend of alcoholic poisonings and alcohol psychoses. Narcology, 1, 25-29. (In Russ.) URL: http://mniiprepo.ru/uploads/1410778899.pdf

Nemtsov A.V., Loshakov E.S. (1997). Kratkaya khronologiya alkogol'nykh psikhozov [Brief chronology of alcoholic psychoses]. Sotsial'naya i klinicheskaya psikhiatriya [Social and Clinical Psychiatry], 7(1), 52-61. (In Russ.)

Peña P. (2015). A not so happy day after all: Excess death rates on birthdays in the U.S. Social Science \& Medicine, 126, 59-66. DOI: https://doi.org/10.1016/j.socscimed.2014.12.014

Phillips D., Barker G., Brewer K. (2010). Christmas and New Year as risk factors for death. Social Science \&Medicine, 71(8), 1463-1471. DOI: https://doi.org/10.1016/j.socscimed.2010.07.024

Phillips D., Christenfeld N., Ryan N. (1999). An increase in the number of deaths in the united states in the first week of the month an association with substance abuse and other causes of death, The New England Journal of Medicine, 341, 93-98. DOI: https://doi.org/10.1056/NEJM199907083410206

Phillips D., Jason R., Abramson I., Phillips R. (2004). Cardiac mortality is higher around Christmas and New Year's than at any other time the holidays as a risk factor for death. Circulation, 110(25), 3781-3788. DOI: https://doi.org/10.1161/01.cir.0000151424.02045.f7

Phillips D., Van Voorhees C., Todd R. (1992). The Birthday: Lifeline or Deadline? Psychosomatic Medicine, 54(5), 532-542. DOI: https://doi.org/10.1097/00006842199209000-00001

Reulbach U., Biermann T., Markovic K., Bleich S. (2007). The myth of the birthday blues: a population-based study about the association between birthday and suicide. Comprehensive Psychiatry, 48(6), 554-557. DOI: https://doi.org/10.1016/j.comppsych.2007.06.006

Shneyder L.B. (2019). Psikhologiya identichnosti [Identity psychology]. 2nd ed., Trans. and additional, Moscow: Izdatel'stvo Yurayt

Stickley A., Sheng Ng C., Inoue Y., Yazawa A., Koyanagi A., Kodaka M., DeVylder J., Watanabe Ch (2016). Birthdays are associated with an increased risk of suicide in Japan: Evidence from 27,007 deaths in Tokyo in 2001-2010. Journal of Affective Disorders, 200, 259-265. DOI: https://doi.org/10.1016/j.jad.2016.04.028

Vaiserman A., Grigoryev P., Belaya I., Voitenko V. (2003). Variation of mortality rate during the individual annual cycle. Biogerontology, 4(4), 221-225. DOI:

https://doi.org/10.1023/A:1025168932058 
Volovikova M.I., Tikhomirova S.V., Borisova A.M. (2003). Psychology and holiday: a holiday in human life. Moscow: PER SE. (In Russ.).

Williams A., While D., Windfuhr K., Bickley H., Hunt I.M., Shaw J., Appleby L., Kapur N. (2011). Birthday Blues, Examining the Association Between Birthday and Suicide in a National Sample. Crisis, 32, 134-142. DOI: https://doi.org/10.1027/0227-5910/a000067

World health organization (2018). Global status report on alcohol and health 2018. Retrieved from https://www.who.int/publications/i/item/9789241565639

Zhaksymbayev M. Dinamika smertnosti ot ubiystv v Rossii [Dynamics of mortality from homicide in Russia]. Demoscope Weekly, 535-536. (In Russ.) Retrieved from http://www.demoscope.ru/weekly/2012/0535/analit09.php

Zubaid M., Thalib L., Suresh C.G. (2006). Incidence of acute myocardial infarction during Islamic holiday seasons. European Journal of Epidemiology, 21(3), 191-195. DOI: https://doi.org/10.1007/s10654-006-0008-8 